\title{
Swarm Intelligence Applications in Electric Machines
}

\author{
Amr M. Amin and Omar T. Hegazy \\ Power and Electrical Machines Department, Faculty of Engineering - Helwan University \\ Egypt
}

\section{Introduction}

Particle Swarm Optimization (PSO) has potential applications in electric drives. The excellent characteristics of PSO may be successfully used to optimize the performance of electric machines in many aspects.

In this chapter, a field-oriented controller that is based on Particle Swarm Optimization is presented. In this system, the speed control of two asymmetrical windings induction motor is achieved while maintaining maximum efficiency of the motor. PSO selects the optimal rotor flux level at any operating point. In addition, the electromagnetic torque is also improved while maintaining a fast dynamic response. A novel approach is used to evaluate the optimal rotor flux level by using Particle Swarm Optimization. PSO method is a member of the wide category of Swarm Intelligence methods (SI). There are two speed control strategies will demonstrate in next sections. These are field-oriented controller (FOC), and FOC based on PSO. The strategies are implemented mathematically and experimental. The simulation and experimental results have demonstrated that the FOC based on PSO method saves more energy than the conventional FOC method.

In this chapter, another application of PSO for losses and operating cost minimization control is presented for the induction motor drives. Two strategies for induction motor speed control are proposed in this section. These strategies are based on PSO and called maximum efficiency strategy and minimum operating cost Strategy. The proposed technique is based on the principle that the flux level in a machine can be adjusted to give the minimum amount of losses and minimum operating cost for a given value of speed and load torque.

In the demonstrated systems, the flux and torque hysteresis bands are the only adjustable parameters to achieve direct torque control (DTC) of induction motors. Their selection greatly influences the inverter switching loss, motor harmonic loss and motor torque ripples, which are the major performance criteria. In this section, the effects of flux and torque hysteresis bands are investigated and optimized by the particle swarms optimization technique. A DTC control strategy with variable hysteresis bands, which improves the drive performance compared to the classical DTC, is presented.

Online Artificial Neural Networks (ANNs) could be also trained based on PSO optimized data. Here the fast response of ANN is used to optimize the operating conditions of the machine. 
It is very important to note that, these applications were achieved without any additional hardware cost, because the PSO is a software scheme. Consequently, PSO has positive promises for a wide range of variable speed drive applications.

\section{Losses Minimization of Two Asymmetrical Windings Induction Motor}

In this section, applying field orientation based on Particle Swarm Optimization (PSO) controls the speed of two-asymmetrical windings induction motor is the first application of PSO. The maximum efficiency of the motor is obtained by the evaluation of optimal rotor flux at any operating point. In addition, the electro-magnetic torque is also improved while maintaining a fast dynamic response. In this section, a novel approach is used to evaluate the optimal rotor flux level. This approach is based on Particle Swarm Optimization (PSO). This section presents two speed control strategies. These are field-oriented controller (FOC) and FOC based on PSO. The strategies are implemented mathematically and experimental. The simulation and experimental results have demonstrated that the FOC based on PSO method saves more energy than the conventional FOC method.

The two asymmetrical windings induction motor is treated as a two-phase induction motor (TPIM). It is used in many low power applications, where three-phase supply is not readily available. This type of motor runs at an efficiency range of $50 \%$ to $65 \%$ at rated operating conditions $[1,2]$.

The conventional field-oriented controller normally operates at rated flux at any values with its torque range. When the load is reduced considerably, the core losses become so high causing poor efficiency. If significant energy savings are required, it is necessary to optimize the efficiency of the motor. The optimum efficiency is obtained by the evaluation of the optimal rotor flux level. This flux level is varied according to the torque and the speed of the operating point.

PSO is applied to evaluate the optimal flux. It has the straightforward goal of minimizing the total losses for a given load and speed. It is shown that the efficiency is reasonably close to optimal.

\subsection{Mathematical Model of the Motor}

The d-q model of an unsymmetrical windings induction motor in a stationary reference frame can be used for a dynamic analysis. This model can take in account the core losses. The $\mathrm{d}$-q model as applied to TPIM is described in [1,2]. The equivalent circuit is shown in fig. 1 . The machine model may be expressed by the following voltage and flux linkage equations :

Voltage Equations:

$$
\begin{gathered}
v_{q s}=r_{m} i_{q s}+p \lambda_{q s} \\
v_{d s}=r_{a} i_{d s}+p \lambda_{d s} \\
0=r_{r} i_{q r}-(1 / k) * \omega_{r} \lambda_{d r}+p \lambda_{q r}
\end{gathered}
$$




$$
\begin{gathered}
0=r_{R} i_{d s}+k * \omega_{r} \lambda_{q r}+p \lambda_{d r} \\
0=-i_{q f e} R_{q f e}+L_{m q}\left(p i_{q s}+p i_{q r}-p i_{q f e}\right) \\
0=-i_{d f e} R_{d f e}+L_{m d}\left(p i_{d s}+p i_{d r}-p i_{d f e}\right)
\end{gathered}
$$

Flux Linkage Equations:

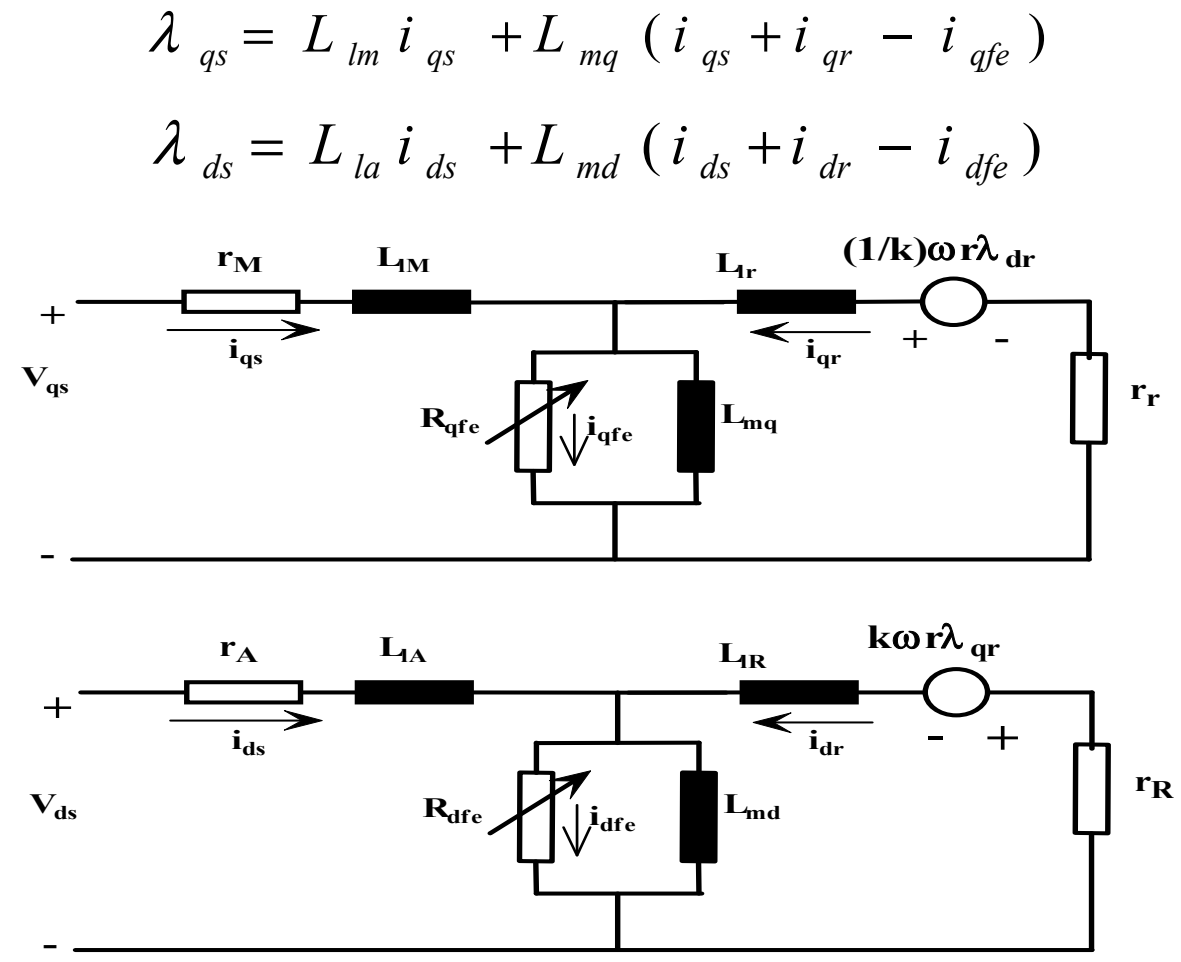

Figure 1. The d-q axes two-phase induction motor Equivalent circuit with iron losses [5]

$$
\begin{gathered}
\lambda_{q r}=L_{l r} i_{q r}+L_{m q}\left(i_{q s}+i_{q r}-i_{q f e}\right) \\
\lambda_{d r}=L_{l R} i_{d r}+L_{m d}\left(i_{d s}+i_{d r}-i_{d f e}\right)
\end{gathered}
$$

Electrical torque equation is expressed as:

$$
T e=\frac{P}{2}\left(k L_{m q} i_{d r}\left(i_{q s}+i_{q r}-i_{q f e}\right)-\frac{1}{k} L_{m d} i_{q r}\left(i_{d s}+i_{d r}-i_{q f e}\right)\right.
$$


Dynamic equation is given as follows:

$$
T e-T_{l}=j_{m} p \omega_{r}+B_{m} \omega_{r}
$$

\subsection{Field-Oriented Controller [FOC]}

The stator windings of the motor are unbalanced. The machine parameters differ from the $\mathrm{d}$ axis to the $q$ axis. The waveform of the electromagnetic torque demonstrates the unbalance of the system. The torque in equation (11) contains an AC term; it can be observed that two values are presented for the referred magnetizing inductance. It is possible to eliminate the AC term of electro-magnetic torque by an appropriate control of the stator currents. However, these relations are valid only in linear conditions. Furthermore, the model is implemented using a non-referred equivalent circuit, which presumes some complicated measurement of the magnetizing mutual inductance of the stator and the rotor circuits [3].

The indirect field-oriented control scheme is the most popular scheme for field-oriented controllers. It provides decoupling between the torque of flux currents. The electric torque must be a function of the stator currents and rotor flux in synchronous reference frame [6]. Assuming that the stator currents can be imposed as:

$$
\begin{aligned}
& i_{d s}^{s}=i_{d s 1}^{s} \\
& i_{q s}^{s}=k i^{s{ }_{q s} 1}
\end{aligned}
$$

Where: $k=M_{s r d} / M_{s r q}$

$$
T_{e}=\frac{P}{2 L_{r}}\left[M_{s q r} i_{q s}^{s} \lambda_{d r}^{s}-M_{s d r} i_{d s}^{s} \lambda_{q r}^{s}\right]
$$

By substituting the variables $\mathbf{i}_{\mathbf{d s}}$, and $\mathbf{i}_{\mathbf{q s}}$ by auxiliary variables $\mathbf{i}_{\mathbf{d s} \mathbf{1}}$, and $\mathbf{i}_{\mathbf{q s} 1}$ into (15) the torque can be expressed by

$$
T_{e}=\frac{P M_{s d r}}{2 L_{r}}\left[i_{q s 1}^{s} \lambda_{d r}^{s}-i_{d s 1}^{s} \lambda_{q r}^{s}\right]
$$

In synchronous reference frame, the electromagnetic torque is expressed as :

$$
\begin{gathered}
T_{e}=\frac{P M_{s d r}}{2 L_{r}}\left[i_{q s 1}^{e} \lambda_{d r}^{e}-i_{d s 1}^{e} \lambda_{q r}^{e}\right] \\
T_{e}=\frac{P M_{s d r}}{2 L_{r}}\left[i_{q s 1}^{e} \lambda_{r}^{e}\right]
\end{gathered}
$$




$$
\begin{aligned}
i_{d s \quad}^{e} & =\frac{\lambda_{r}^{e}}{M{ }_{s d r}} \\
\omega_{e}-\omega_{r} & =\frac{M_{s d r}}{\tau_{r} * \lambda_{r}} i_{q s 1}^{e}
\end{aligned}
$$

\subsection{Model with the Losses of two asymmetrical windings induction motor}

Finding the losses expression for the two asymmetrical windings induction motor with losses model is a very complex. In this section, a simplified induction motor model with iron losses will be developed [4]. For this purpose, it is necessary to transform all machine variables to the synchronous reference frame. The voltage equations are written in expanded form as follows:

$$
\begin{gathered}
v_{q s}^{e}=r_{m} i_{q s}^{e}+L_{l m} \frac{d i_{q s}^{e}}{d t}+L_{m q} \frac{d i_{q m}^{e}}{d t}+\omega_{e}\left(L_{l a} i_{d s}^{e}+L_{m d} i_{d m}^{e}\right) \\
v_{d s}^{e}=r_{a} i_{d s}^{e}+L_{l a} \frac{d i_{d s}^{e}}{d t}+L_{m d} \frac{d i_{d m}^{e}}{d t}-\omega_{e}\left(L_{l m} i_{q_{s}}^{e}+L_{m q} i_{q m}^{e}\right) \\
0=r_{r} i_{q r}^{e}+L_{l r} \frac{d i_{q r}^{e}}{d t}+L_{m q} \frac{d i_{q m}^{e}}{d t}+\frac{\omega_{s l}}{k}\left(L_{l R} i_{d r}^{e}+L_{m d} i_{d m}^{e}\right) \\
0=r_{R} i_{d r}^{e}+L_{l R} \frac{d i_{d r}^{e}}{d t}+L_{m d} \frac{d i_{d m}^{e}}{d t}-k * \omega_{s l}\left(L_{l r} i_{q r}^{e}+L_{m q} i_{q m}^{e}\right) \\
i_{q s}^{e}+i_{q r}^{e}=i_{q f e}^{e}+i_{q m}^{e} \\
i_{d s}^{e}+i_{d r}^{e}=i_{d f e}^{e}+i_{d m}^{e}
\end{gathered}
$$

Where:

$$
\begin{gathered}
i_{d f e}^{e}=\frac{v_{q m}^{e}}{R_{q f e}} ; i_{d f e}^{e}=\frac{v_{d m}^{e}}{R_{d f e}} \\
v_{d m}^{e}=-\frac{\omega_{e} L_{l r} L_{m q s}}{L_{r}} i_{q s}^{e}
\end{gathered}
$$




$$
v_{q m}^{e}=\omega_{e} L_{m d s} i_{d s}^{e}
$$

The losses in the motor are mainly:

a. Stator copper losses,

b. Rotor copper losses,

c. Core losses, and

d. Friction losses.

The total electrical losses can be expressed as follows

$$
\mathrm{P}_{\text {losses }}=\mathrm{P}_{\mathrm{cu} 1}+\mathrm{P}_{\mathrm{cu} 2}+\mathrm{P}_{\text {cor }}
$$

Where:

$\mathrm{P}_{\text {cu1 }}$ : Stator copper losses

$\mathrm{P}_{\text {cu2 }}$ : $\quad$ Rotor copper losses

$P_{\text {core: }} \quad$ Core losses

The stator copper losses of the two asymmetrical windings induction motor are caused by electric currents flowing through the stator windings. The core losses of the motor due to hysteresis and eddy currents in the stator. The total electrical losses of motor can be rewritten as:

$$
P_{\text {losses }}=r_{m} i_{q s}^{e^{2}}+r_{a} i_{d s}^{e^{2}}+r_{r} i_{q r}^{e^{2}}+r_{R} i_{d r}^{e^{2}}+\frac{v_{q m}^{e^{2}}}{R_{q f e}}+\frac{v_{d m}^{e^{2}}}{R_{d f e}}
$$

The total electrical losses are obtained as follows:

$$
P_{\text {losses }}=\left[r_{m}+\frac{r_{r} L_{m q s}^{2}}{L_{r}^{2}}+\frac{\omega_{e}^{2} L_{l r}^{2} L_{m q s}^{2}}{L_{r}^{2} R_{d f e}}\right]\left(\frac{T_{e}^{2} L_{r}^{2}}{P^{2}\left(\frac{L_{m d s}}{K}\right)^{2} \lambda_{r}^{2}}\right)+\left(r_{a}+\frac{\omega_{e}^{2} L_{m d s}^{2}}{R_{q f e}}\right) \frac{\lambda_{r}^{2}}{L_{m d s}^{2}}
$$

Where:

$\omega_{\mathrm{e}}=\omega_{\mathrm{r}}+\omega_{\mathrm{sl}}$, and $\omega_{\mathrm{sl}}$ is the slip speed $\mathrm{r} / \mathrm{sec}$.

$$
\omega_{s l}=\frac{2 T_{e}{ }^{*} r_{r}}{P * \lambda_{r}^{2}}
$$

Equation (31) is the electrical losses formula, which depends on rotor flux ( $\lambda \mathrm{r})$ according to operating point (speed and load torque).

$$
\begin{aligned}
\text { Total } P_{\text {losses }}\left(\mathrm{TP}_{\text {losses }}\right) & =\mathrm{P}_{\text {losses }}+\text { friction power losses } \\
& =\mathrm{P}_{\text {in }}-\mathrm{P}_{\text {out }} \\
\text { Efficiency }(\eta) & =\text { Po } /\left(\operatorname{Po}+\text { Total } P_{\text {losses }}\right)
\end{aligned}
$$


Where:

Friction power losses $=\mathrm{F} * \omega_{\mathrm{r}}^{2}$, and

Output power $(\mathrm{Po})=\mathrm{T}_{\mathrm{L}} * \omega_{\mathrm{r}}$.

The equation (31) is the cost function, which depends on rotor flux $\left(\lambda_{\mathrm{r}}\right)$ according to the operating point. Figure 2 presents the distribution of losses in motor and its variation with the flux. As the flux reduces from the rated value, the core losses decrease, but the motor copper losses increase. However, the total losses decrease to a minimum value and then increase again. It is desirable to set the rotor flux at the optimal value, so that the efficiency is optimum.

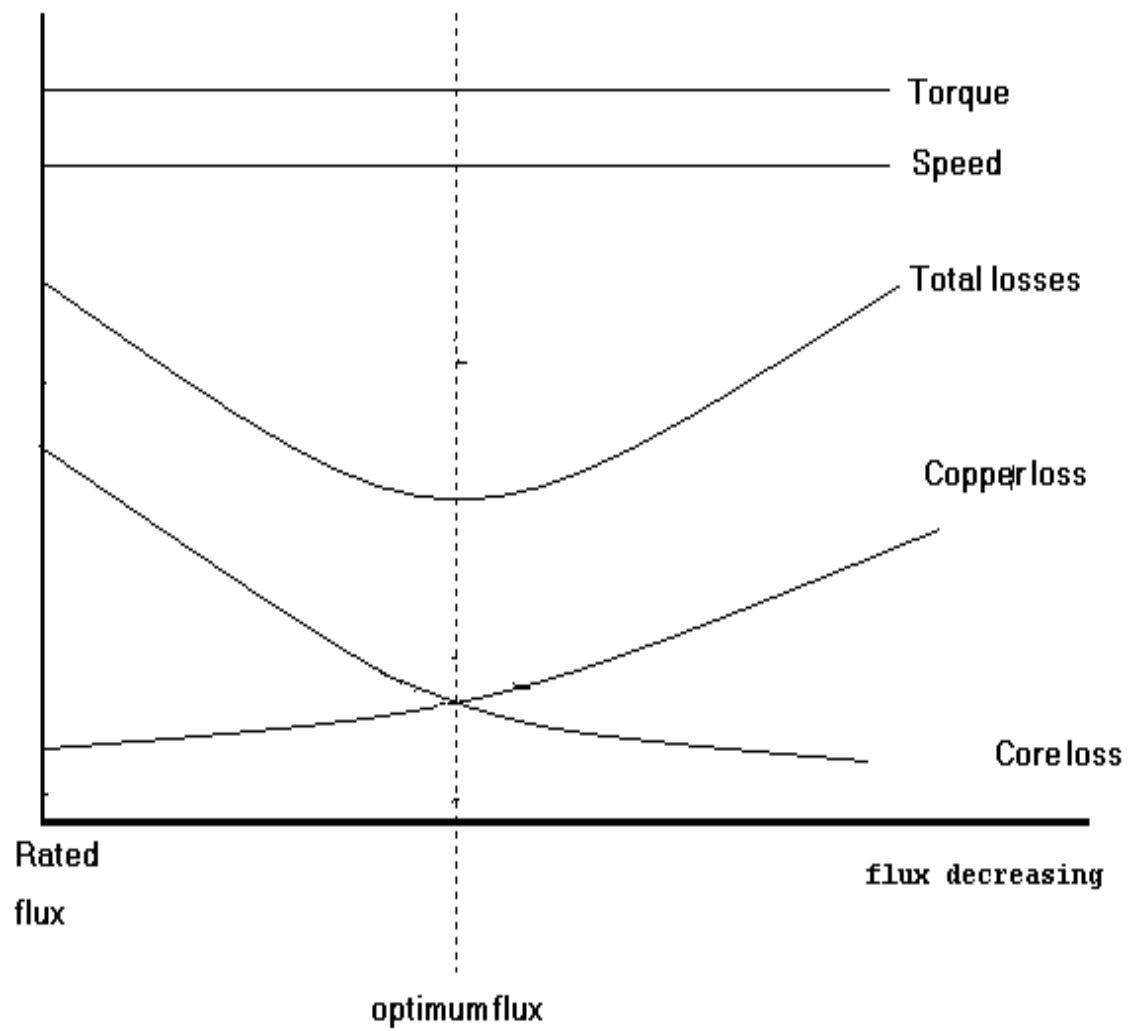

Figure 2. Losses variation of the motor with varying flux

The function of the losses minimization of the motor problem can be formulated as follows: Minimize Total Losses which are a function of $\lambda$, Te, and $\omega r$

- The losses formula is the cost function of PSO. The particle swarm optimization (PSO) technique is used for minimizing this cost function.

- $\quad$ The PSO is applied to evaluate the optimal rotor flux that minimizes the motor losses at any operating point. Figure 3 presents the flowchart of the execution of PSO, which evaluates the optimal flux by using MATLAB /SIMULINK. 


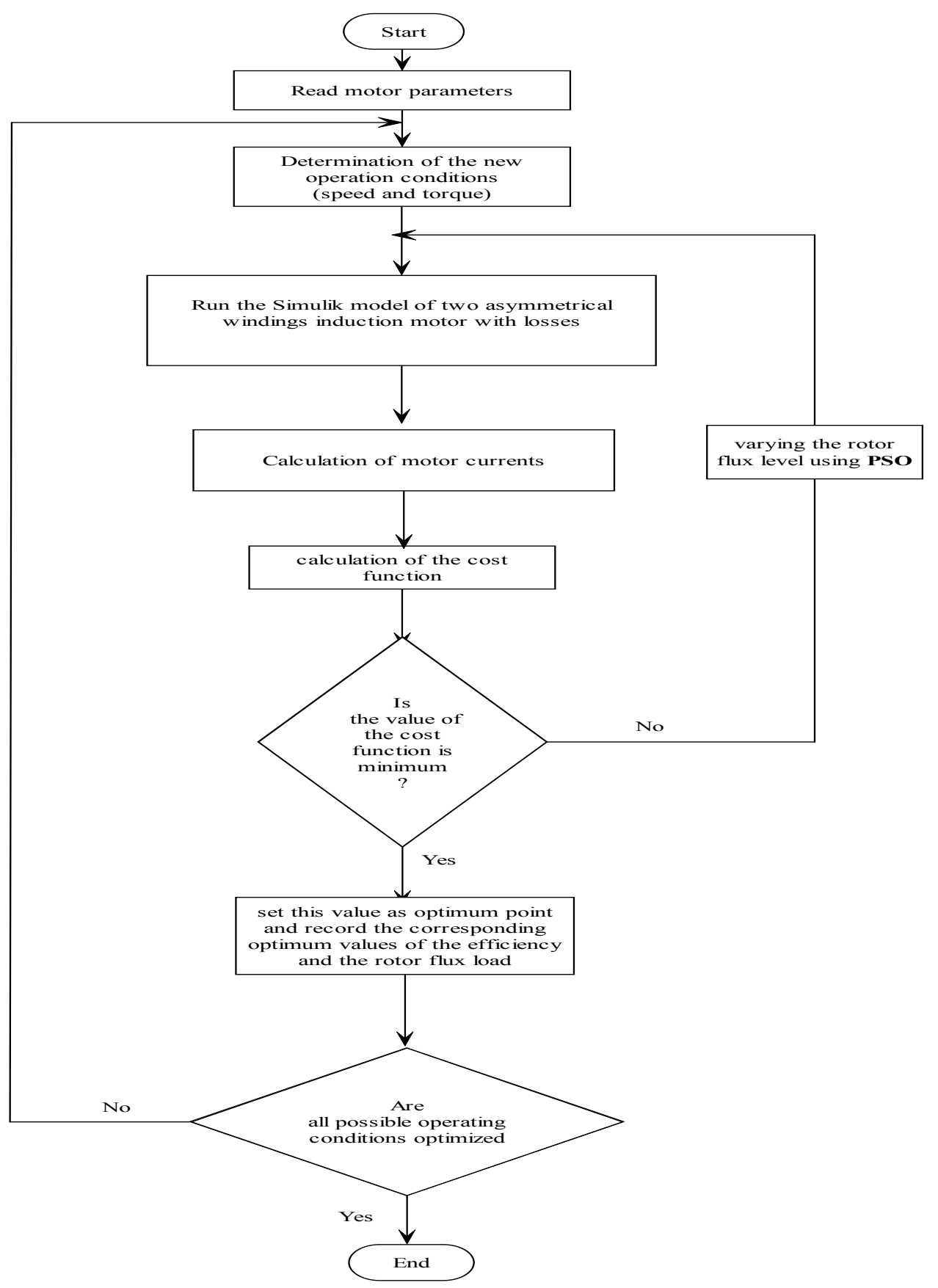

Figure 3. The flowchart of the execution of PSO 
The optimal flux is the input of the indirect rotor flux oriented controller. The indirect fieldoriented controller generates the required two reference currents to drive the motor corresponding to the optimal flux. These currents are fed to the hysteresis current controller of the two-level inverter. The switching pattern is generated according to the difference between the reference current and the load current through the hysteresis band. Figure 4 shows a whole control diagram of the proposed losses-minimization control system.

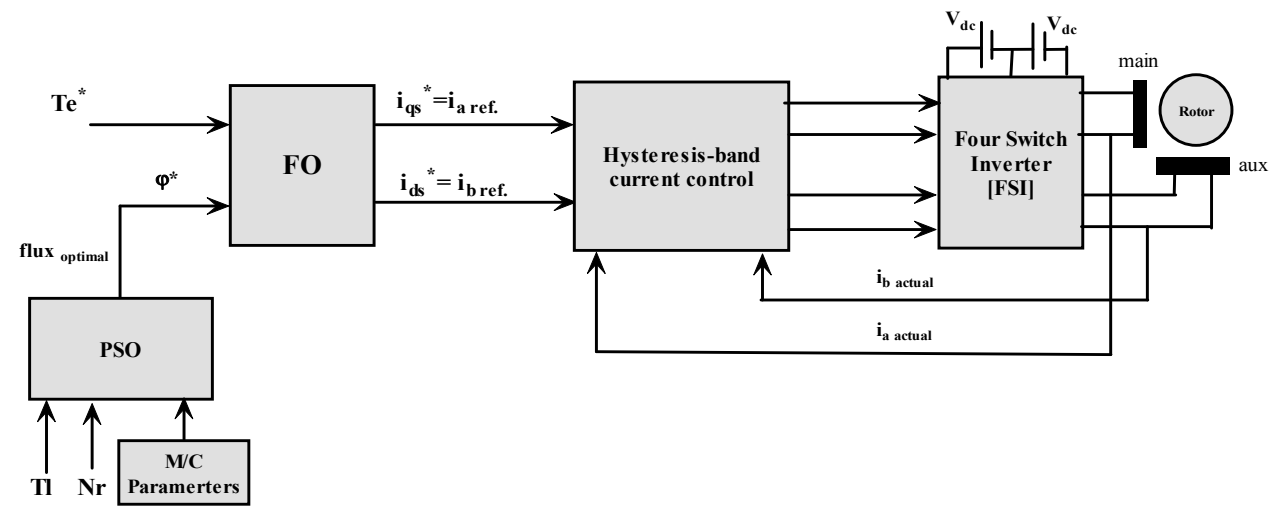

Figure 4. Proposed losses minimization control system

\subsection{Simulation study with FOC}

The motor used in this study has the following parameters, which were measured by using experimental tests. The FOC module is developed with closed loop speed control. The input of the FOC module is the reference speed and the rated rotor flux. The fieldoriented controller generates the required reference currents to drive the motor as shown in fig.5. These currents are based on the flux level, which determines the value of direct current, and the reference torque, which determines the value of quadrature current. The reference torque is calculated according to the speed error. In this section, six-cases of motor operation with FOC are presented.

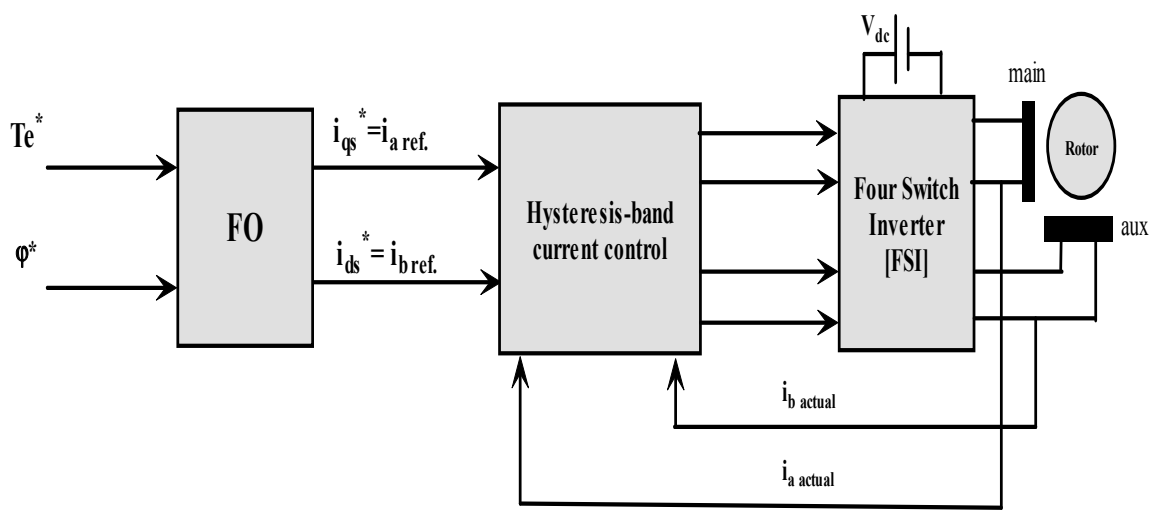

Figure 5. Block diagram of indirect rotor flux oriented control of the motor 
Figure 6 shows the performance of the motor at case (1), where the motor is loaded by 0.25p.u. The control technique based on the PI controller has been developed. The proportional $(\mathrm{Kp})$ and integral $(\mathrm{Ki})$ constants of PI controller are chosen by trial and error. The speed-time curve for the motor is shown in fig. 6a. It is noticed that the speed oscillations are eliminated when the FOC is applied to the drive system.

Figure $6 \mathrm{~b}$ illustrates the developed torque-time curve of the motor. In this figure, the pulsating torque is eliminated.

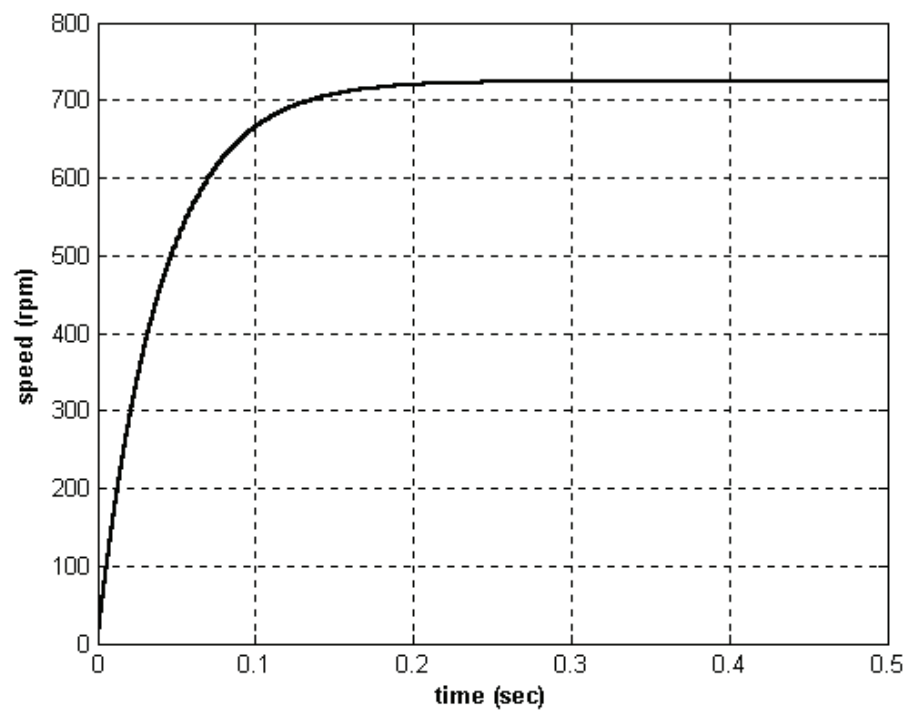

(a)

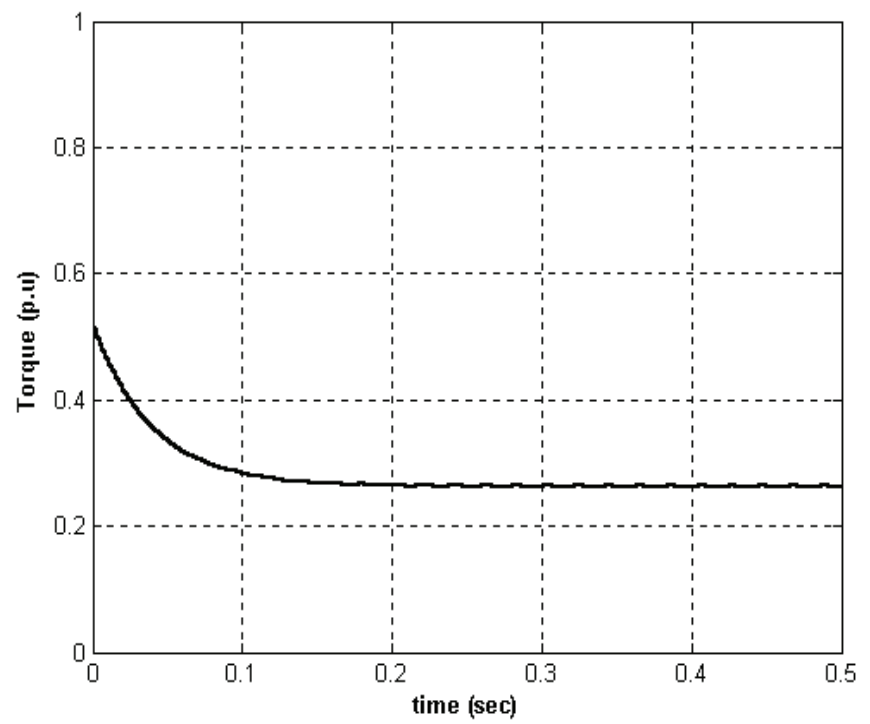

(b) 


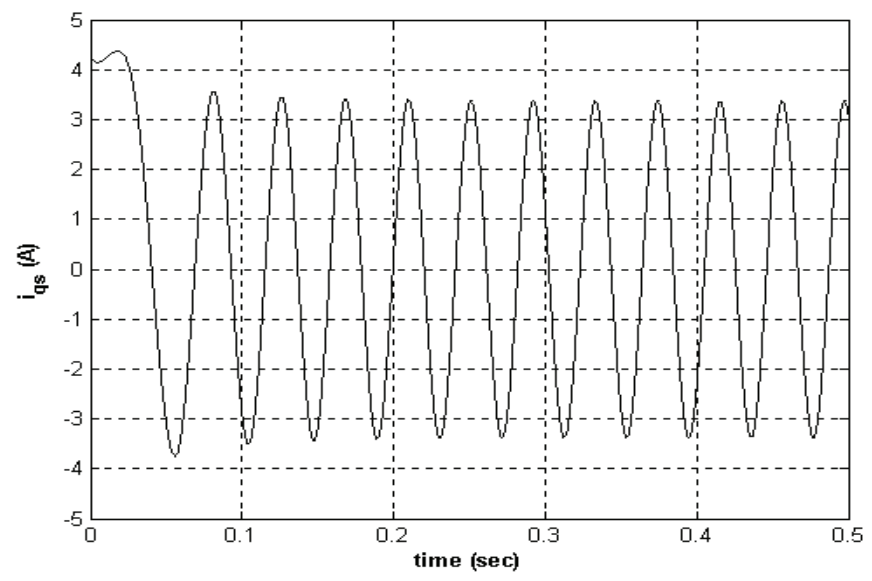

(c)

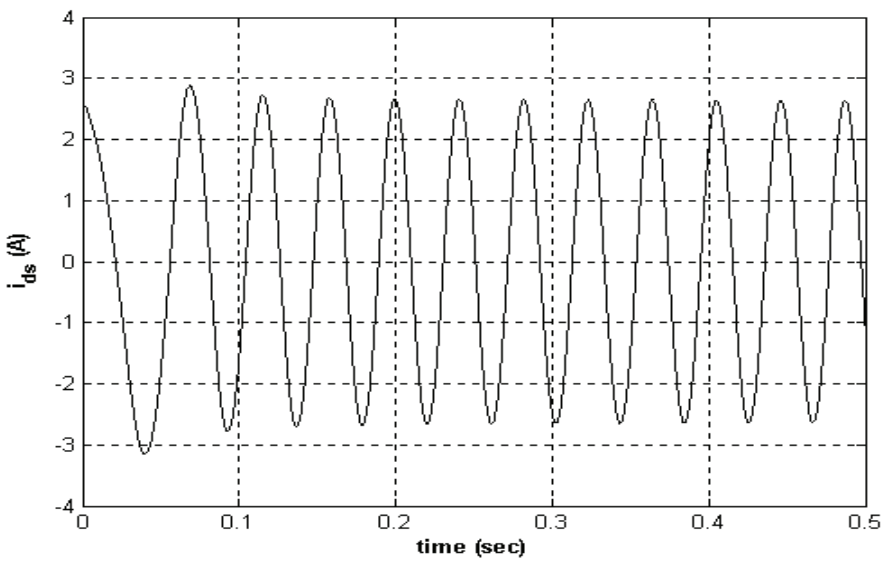

(d)

Figure 6. Simulation results of the motor at case (1), (a) Speed-time curve, (b) Torque-time curve, (c)The stator current in q-axis, (d) the stator current in d-axis

The efficiency is calculated from equation (33). Therefore, the efficiency is found to be equal to $33.85 \%$. The six-cases are summarized in Table 1.

\begin{tabular}{|l|l|l|l|}
\hline $\begin{array}{l}\text { Torque load }\left(\mathrm{T}_{\mathrm{L}}\right) \\
\text { p.u }\end{array}$ & Speed $(\mathrm{N})$ & $\begin{array}{l}\text { Flux rated } \\
\text { p.u }\end{array}$ & Efficiency (\%) \\
\hline 0.25 & $0.5 \mathrm{~N}_{\text {rated }}$ & 1 & 33.85 \\
\hline 0.375 & $0.5 \mathrm{~N}_{\text {rated }}$ & 1 & 36.51 \\
\hline 0.5 & $0.5 \mathrm{~N}_{\text {rated }}$ & 1 & 48.21 \\
\hline 0.6125 & $0.5 \mathrm{~N}_{\text {rated }}$ & 1 & 55.15 \\
\hline 0.75 & $0.5 \mathrm{~N}_{\text {rated }}$ & 1 & 60.175 \\
\hline 1 & $0.5 \mathrm{~N}_{\text {rated }}$ & 1 & 63.54 \\
\hline
\end{tabular}

Table 1 . The summary of the cases 
It is clear that, the indirect field-oriented controller with a rated rotor flux generally exhibits poor efficiency of the motor at light load. If significant energy savings need to be obtained, it is necessary to optimize the efficiency of the motor. The optimum efficiency of the motor is obtained by the evaluation of the optimal rotor flux level.

\subsection{Losses minimization control scheme}

As swarm intelligence is based on real life observations of social animals (usually insects), it is more flexibility and robust than any traditional optimization methods. PSO method is a member of the wide category of swarm intelligence methods (SI). In this section, PSO is applied to evaluate the optimal flux that minimizes the motor losses. The problem can be formulated as follows:

Minimize Total Losses which are a function of $\lambda, \mathrm{Te}$, and $\omega \mathrm{r}$

- The motor used as a two-asymmetrical windings induction motor. The parameters used are shown in Table 2 [10].

\begin{tabular}{|c|c|}
\hline Parameters & Value \\
\hline Population size & 10 \\
\hline Max. iter & 50 \\
\hline c1 & 0.5 \\
\hline c2 & 0.5 \\
\hline Max. weight & 1.4 \\
\hline Min. weight & 0.1 \\
\hline r1 & {$[0,1]$} \\
\hline r2 & {$[0,1]$} \\
\hline Lbnd & 0.2 \\
\hline upbnd & 2 \\
\hline
\end{tabular}

Table 2. PSO Algorithm Parameters

A simplified block diagram of the proposed speed control scheme is shown in fig.7.

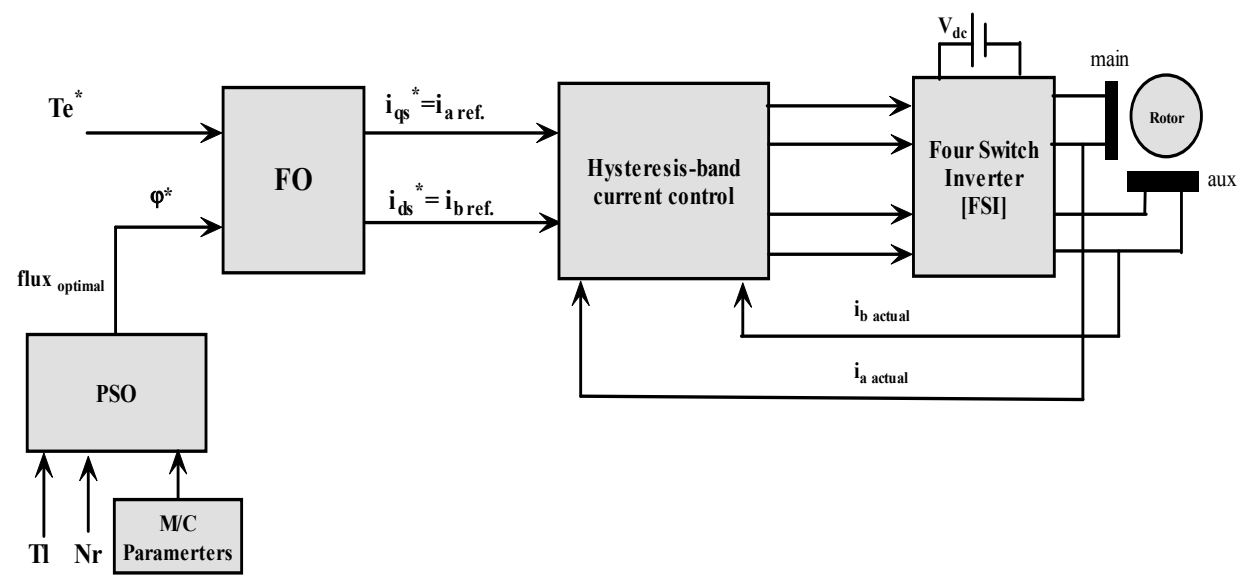

Figure 7. Proposed losses minimization control system 
A Four-Switch Inverter (FSI) feeds the two-asymmetrical windings induction motor. The optimal flux is fed to the indirect rotor flux oriented control. The indirect field-oriented control generates the required reference current to drive the motor corresponding to this flux

\subsection{Simulation results with FO based on PSO}

The optimal rotor flux provides the maximum efficiency at any operating point, next the previous six-cases are repeated by using FOC based on PSO. PSO will evaluate the optimal rotor flux level. This flux is fed to the FOC module. Figure 8 shows the performance of the motor at case (1), when PSO is applied side-by-side FOC.

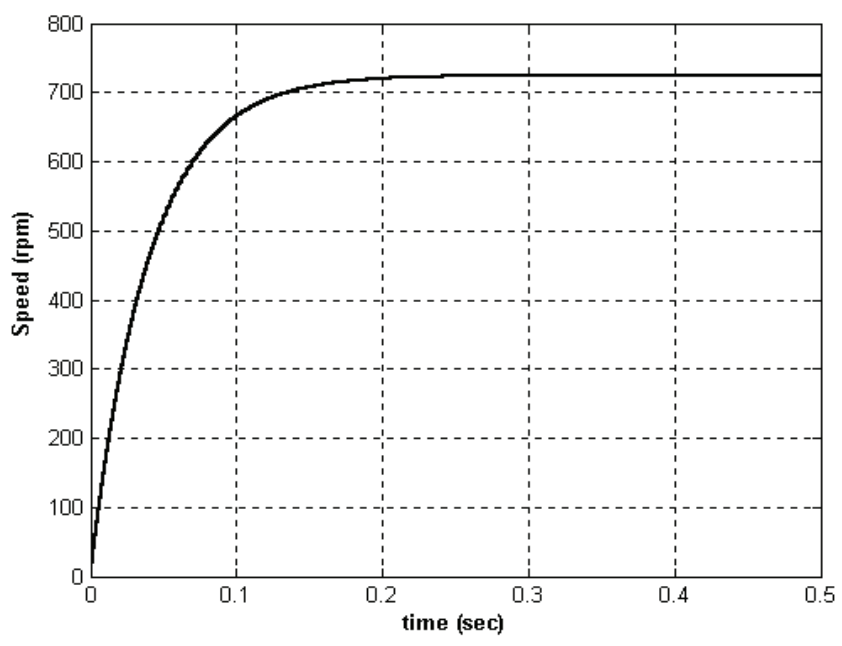

(a)

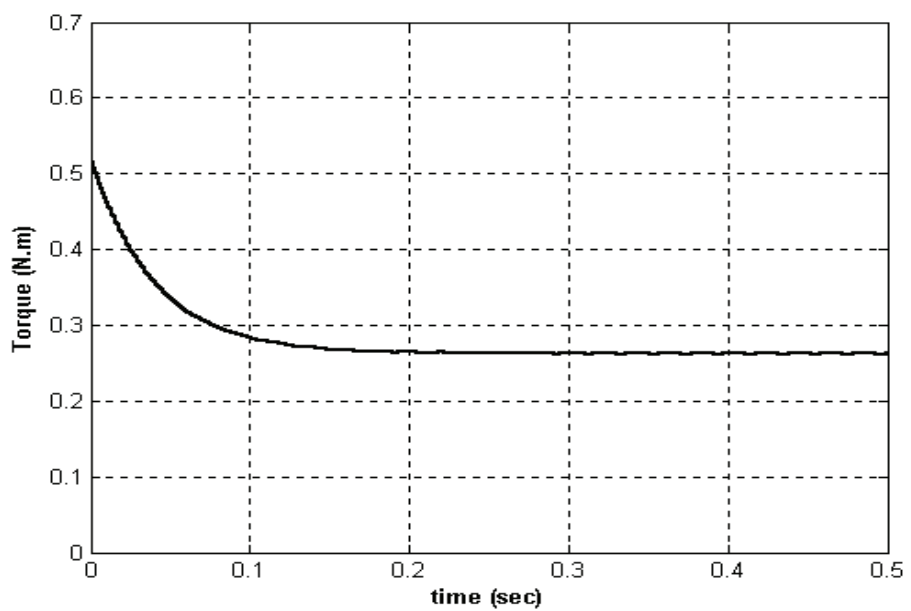

(b) 


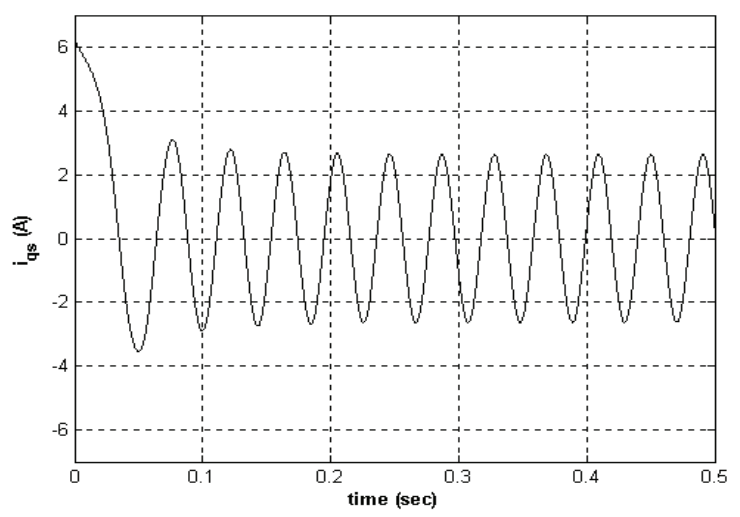

(c)

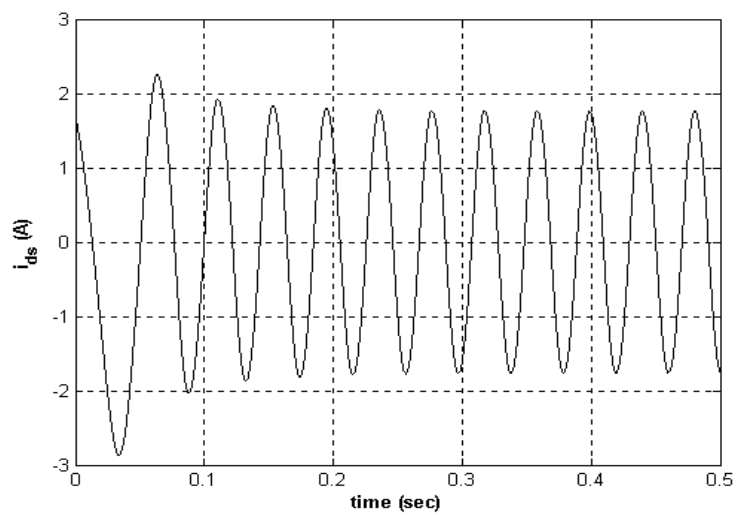

(d)

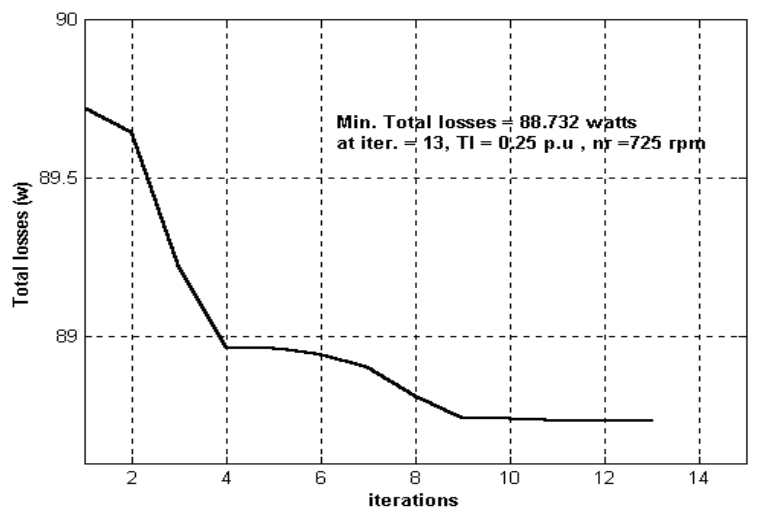

(e)

Figure 8. Simulation results of the motor at case (1). (a) Speed-time curve, (b)Torque-time curve, (c) The stator current in q-axis, (d) The stator current in d-axis, (e) Total Losses against iterations 
It is noticed that, the PSO implementation increased the efficiency of the motor to $46.11 \%$ at half the rated speed. The six-cases are summarized in Table 3.

\begin{tabular}{|c|c|c|c|}
\hline $\begin{array}{c}\text { Torque load } \\
\text { (TL) p.u }\end{array}$ & Speed (N) & Optimal flux(p.u) & Efficiency (\%) \\
\hline 0.25 & 0.5 Nrated & 0.636 & 46.11 \\
\hline 0.375 & 0.5 Nrated & 0.6906 & 49.15 \\
\hline 0.5 & 0.5 Nrated & 0.722 & 57.11 \\
\hline 0.6125 & 0.5 Nrated & 0.761 & 62.34 \\
\hline 0.75 & 0.5 Nrated & 0.8312 & 65.31 \\
\hline 1 & 0.5 Nrated & 0.8722 & 68.15 \\
\hline
\end{tabular}

Table 3. The summary of the six-cases at optimal flux

In practical system, the flux level based on PSO at different operating points (torque and speed) is calculated and stored in a look up table. The use of look up table will enable the system to work in real time without any delay that might be needed to calculate the optimal point. The proposed controller would receive the operating point (torque and speed) and get the optimum flux from the look up table. It will generate the required reference current. It is noticed that, the efficiency with the FOC based on PSO method is higher than the efficiency with the FOC method only.

\subsection{Experimental Results}

To verify the validity of the proposed control scheme, a laboratory prototype is built and tested. The basic elements of the proposed experimental scheme are shown in fig. 9 and fig. 10. The experimental results of the motor are achieved by coupling the motor to an eddy current dynamometer. The experimental results are achieved using two control methods:

- $\quad$ Field-Oriented Control [FOC], and

- $\quad$ Field-Oriented Control [FOC] based on PSO.

The reference and the actual motor currents are fed to the hysteresis current controller. The switching pattern of the two-level four-switch inverter [FSI] is generated according to the difference between the reference currents and the load currents. Figure 11 shows the experimental results of the motor with FOC at case (1), where the motor is loaded by $\mathrm{Tl}=$ 0.25 p.u.

The measured input power of the motor is about 169 watts, and then the efficiency is calculated about $44.92 \%$, whereas the efficiency with FOC is $32.30 \%$. It is noticed that, the PSO implementation increased the efficiency of the motor by $12.62 \%$. The cases are summarized in Table 4 as follows.

\begin{tabular}{|c|c|c|c|c|c|c|}
\hline \multirow{2}{*}{ Cases } & \multicolumn{3}{|c|}{ FOC } & \multicolumn{3}{c|}{ FOC with PSO } \\
\cline { 2 - 7 } & $\begin{array}{c}\text { Flux } \\
\text { p.u }\end{array}$ & $\begin{array}{c}\text { Power } \\
\text { Input }\end{array}$ & $\begin{array}{c}\eta \\
(\%)\end{array}$ & $\begin{array}{c}\text { Flux } \\
\text { p.u }\end{array}$ & $\begin{array}{c}\text { Power } \\
\text { Input }\end{array}$ & $\begin{array}{c}\eta \\
(\%)\end{array}$ \\
\hline$(1)$ & 1 & 235 & 32.3 & 0.636 & 169 & 44.92 \\
\hline$(2)$ & 1 & 323 & 35.2 & 0.690 & 243 & 47.06 \\
\hline
\end{tabular}

Table 5 the summary of the two-cases 
The improvement of the efficiency in case (1) is around $12.62 \%$ when PSO is applied. The improvement of the efficiency in case (2) is around $11.84 \%$, where the motor is loaded by $\mathrm{Tl}$ $=0.375$ p.u. These results demonstrate that, the FOC based on PSO method saves more energy than conventional FOC method. Thus, the efficiency with PSO is improved than it's at FOC.

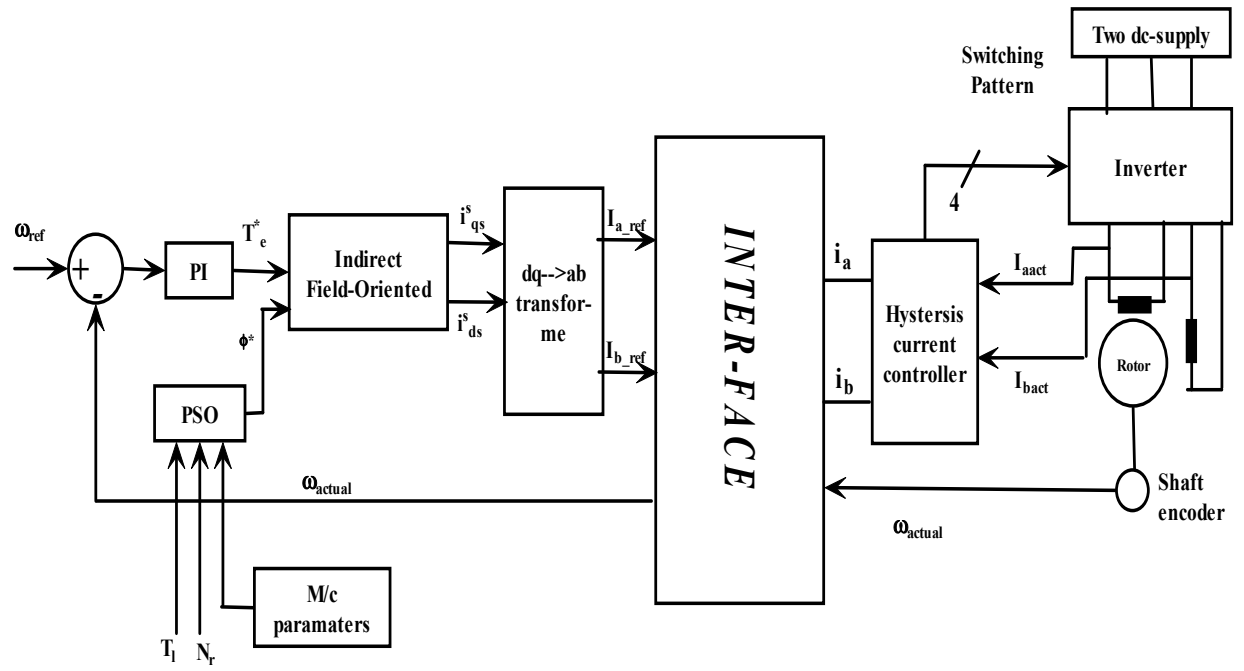

Figure 9. Block diagram of the proposed drive system

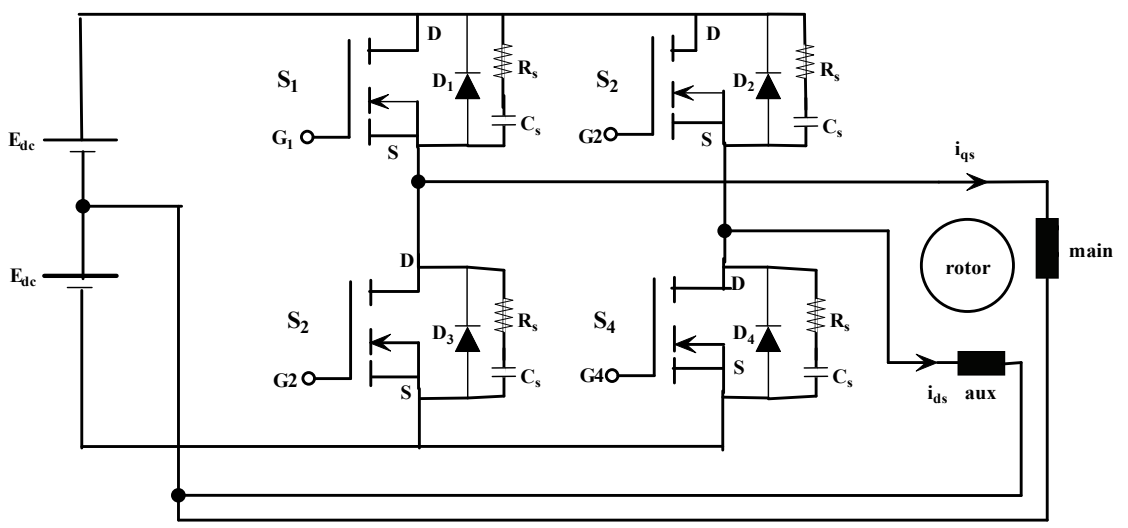

Figure 10. The power circuit of Four Switch inverter [FSI] 


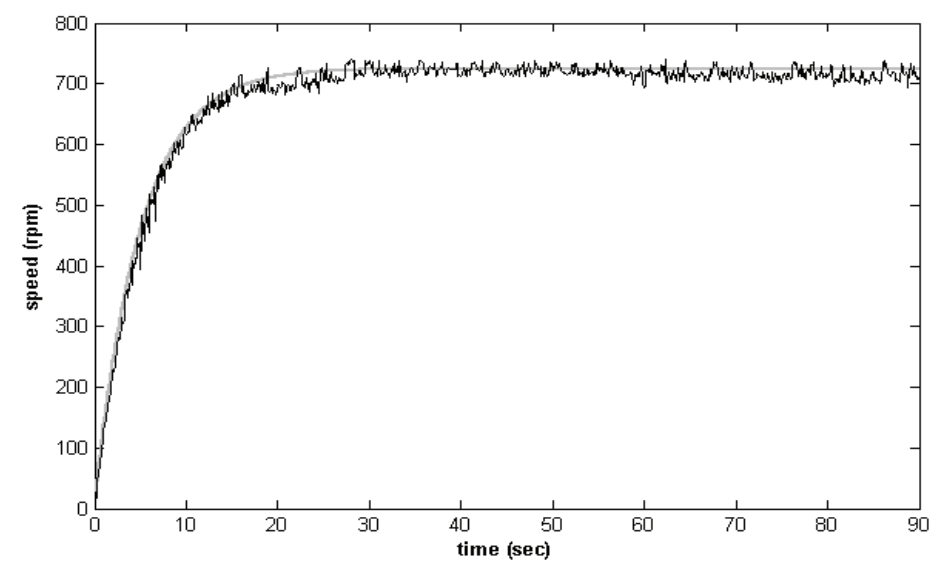

(a)

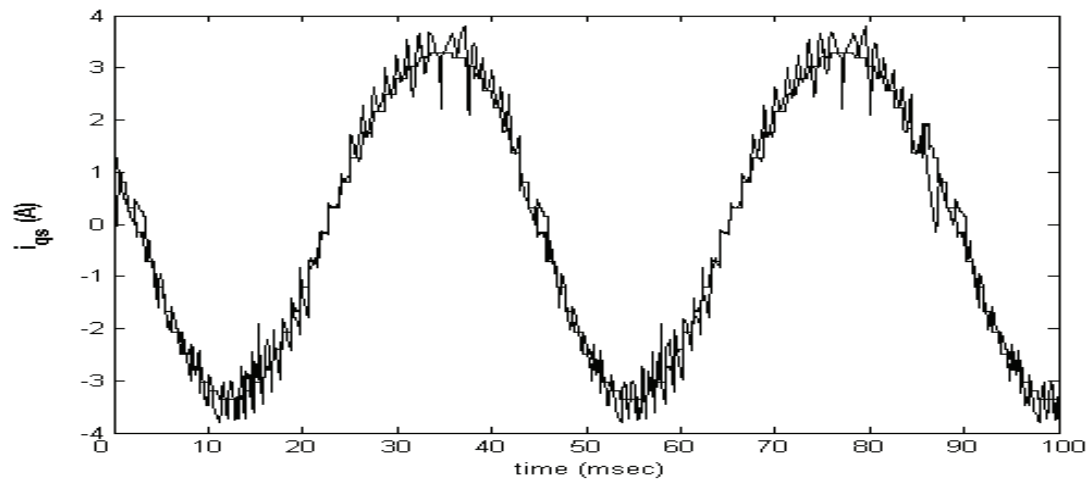

(b)

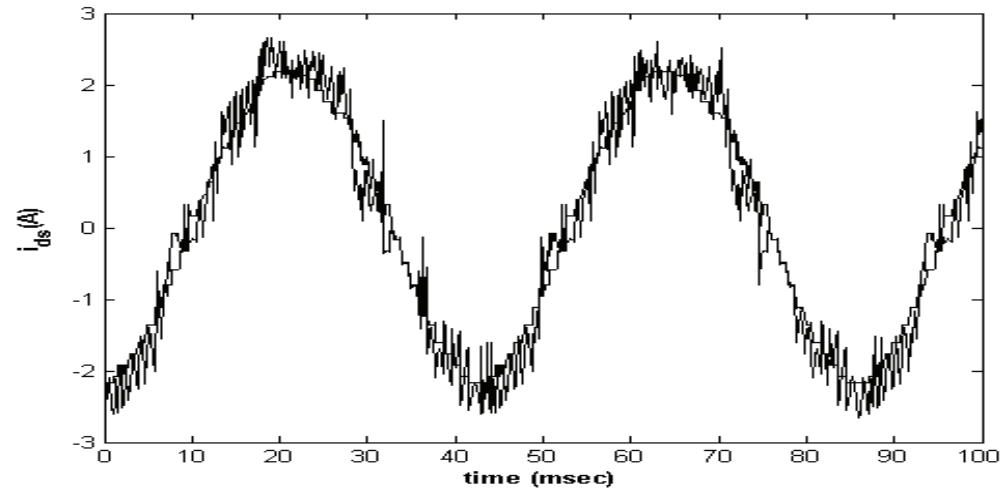

(c)

Figure 11. Experimental results of FOC method. (a)The reference and actual speed, (b) The reference and actual current in q-axis, (c) The reference and actual current in d-axis 
The measured total input power of the motor is 235 watts. The efficiency is calculated from equation (33). The efficiency is found to be equal to $32.30 \%$. Figure 11 shows the experimental result of the motor with FOC based on PSO at case (1).

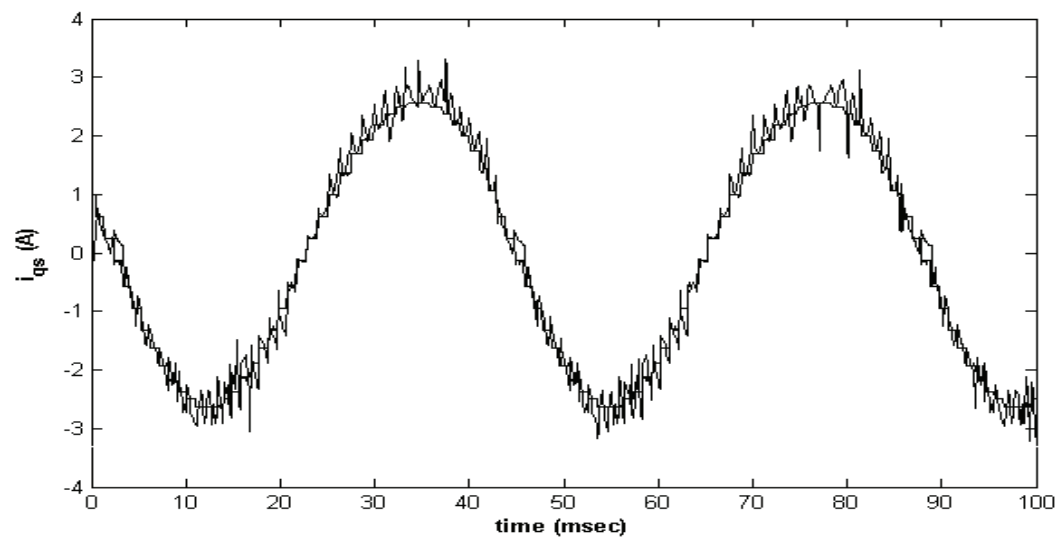

(a)

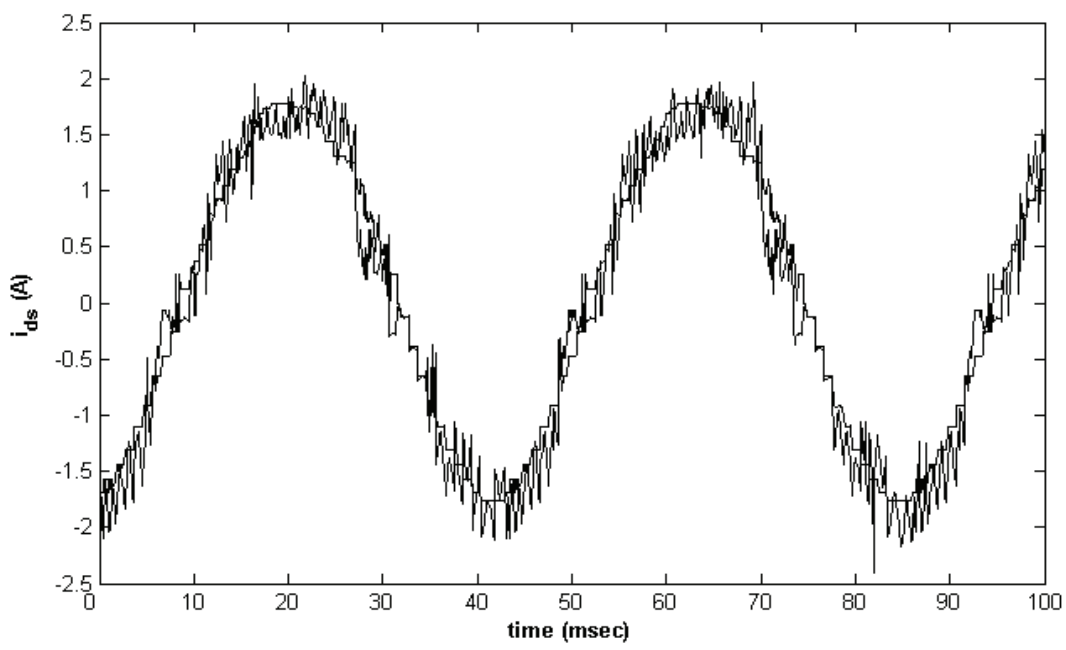

(b)

Figure 11. Experimental results of FOC method based on PSO. (a) The reference and actual current in q-axis, (b)The reference and actual current in d-axis

\section{Maximum Efficiency and Minimum Operating Cost of Induction motors}

This section presents another application of PSO for losses and operating cost minimization control in the induction motor drives. In this paper, two strategies for induction motor speed control are proposed. Those two strategies are based on PSO and called Maximum 
Efficiency Strategy and Minimum Operating Cost Strategy. The proposed technique is based on the principle that the flux level in the machine can be adjusted to give the minimum amount of losses and minimum operating cost for a given value of speed and load torque. The main advantages of the proposed technique are; its simple structure and its straightforward maximization of induction motor efficiency and its operating cost for a given load torque. As will be demonstrated, PSO is so efficient in finding the optimum operating machine's flux level. The optimum flux level is a function of the machine operating point.

Simulation results show that a considerable energy and cost savings are achieved in comparison with the conventional method of operation under the condition of constant voltage to frequency ratio $[5,6]$.

It is estimated that, electric machines consume more than $50 \%$ of the world electric energy generated. Improving efficiency in electric drives is important, mainly, for two reasons: economic saving and reduction of environmental pollution. Induction motors have a high efficiency at rated speed and torque. However, at light loads, the iron losses increase dramatically, reducing considerably the efficiency. The main induction motor losses are usually split into 5 components: stator copper losses, rotor copper losses, iron losses, mechanical losses, and stray losses.

The efficiency that decreases with increasing losses can be improved by minimizing the losses. Copper losses reduce with decreasing the stator and the rotor currents, while the core losses essentially increase with increasing air-gap flux density. A study of the copper and core losses components reveals that their trends conflict. When the core losses increase, the copper losses tends to decrease. However, for a given load torque, there is an air-gap flux density at which the total losses is minimized. Hence, electrical losses minimization process ultimately comes down to the selection of the appropriate air-gap flux density of operation. Since the air-gap flux density must be variable when the load is changing, control schemes in which the (rotor, air-gap) flux linkage is constant will yield sub-optimal efficiency operation especially when the load is light. Then to improve the motor efficiency, the flux must be reduced when it operates under light load conditions by obtaining a balance between copper and iron losses.

The challenge to engineers, however, is to be able to predict the appropriate flux values at any operating points over the complete torque and speed range which will minimize the machines losses, hence maximizing the efficiency. In general, there are three different approaches to improve the induction motor efficiency especially under light-load conditions.

\section{a. Losses Model Controller (LMC)}

This controller depends on a motor losses model to compute the optimum flux analytically. The main advantage of this approach is its simplicity and it does not require extra hardware. In addition, it provides smooth and fast adaptation of the flux, and may offer optimal performance during transient operation. However, the main problem of this approach is that it requires the exact values of machine parameters. These parameters include the core losses and the main inductance flux saturation, which are unknown to the users and change considerably with temperature, saturation, and skin effect. In addition, these parameters may vary due to changes in the operating conditions. However, with continuing 
improvement of evolutionary parameter determination algorithms, the disadvantages of motor parameters dependency are slowly disappearing.

\section{b. Search Controller (SC)}

This controller measures the input power of the machine drive regularly at fixed time intervals and searches for the flux value, which results in minimum power input for given values of speed and load torque [5]. This particular method does not demand knowledge of the machine parameters and the search procedure is simple to implement.

However, some disadvantages appear in practice, such as continuous disturbances in the torque, slow adaptation (7sec.), difficulties in tuning the algorithm for a given application, and the need for precise load information. In addition, the precision of the measurements may be poor due to signal noise and disturbances. This in turn may cause the SC method to give undesirable control performance. Moreover, nominal flux is applied in transient state and is tuned after the system reaches steady state to an optimal value by numerous increments, thus lengthening the optimization process. Therefore, the SC technique may be slow in obtaining the optimal point. In addition, in real systems, it may not reach a steady state and so cause oscillations in the air gap flux that result in undesirable torque disturbances. For these reasons, this is not a good method in industrial drives.

\section{c. Look Up Table Scheme}

It gives the optimal flux level at different operating points. This table, however, requires costly and time-consuming prior measurements for each motor. In this section, a new control strategy uses the loss model controller based on PSO is proposed. This strategy is simple in structure and has the straightforward goal of maximizing the efficiency for a given load torque. The resulting induction motor efficiency is reasonably close to optimal. It is well known that the presence of uncertainties ,the rotor resistance, for instance makes the result no more optimal. Digital computer simulation results are obtained to demonstrate the effectiveness of the proposed method.

\subsection{Differences between PSO and Other Evolutionary Computation (EC) Techniques}

The most striking difference between PSO and the other evolutionary algorithms is that PSO chooses the path of cooperation over competition. The other algorithms commonly use some form of decimation, survival of the fittest. In contrast, the PSO population is stable and individuals are not destroyed or created. Individuals are influenced by the best performance of their neighbors. Individuals eventually converge on optimal points in the problem domain. In addition, the PSO traditionally does not have genetic operators like crossover between individuals and mutation, and other individuals never substitute particles during the run. Instead, the PSO refines its search by attracting the particles to positions with good solutions. Moreover, compared with genetic algorithms (GAs), the information sharing mechanism in PSO is significantly different. In GAs, chromosomes share information with each other. So the whole population moves like a one group towards an optimal area. In PSO, only Gbest (or Pbest) gives out the information to others. It is a oneway information sharing mechanism. The evolution only looks for the best solution. In PSO, all the particles tend to converge to the best solution quickly, comparing with GA, even in the local version in most cases $[7,8]$. 


\subsection{Definition of Operating Strategies}

The following definitions are useful in subsequent analyses. Referring to the analysis of the induction motor presented in [3], the per-unit frequency is

$$
a=\frac{\omega_{e}}{\omega_{b}}=\frac{\omega_{s}+\omega_{r}}{\omega_{b}}
$$

The slip is defined by

$$
s=\frac{\omega_{s}}{\omega_{e}}=\frac{\omega_{s}}{\omega_{s}+\omega_{r}}
$$

The rotor current is given by

$$
I_{r}^{\prime}=\frac{\phi_{{ }_{m}}}{\sqrt{\left(\frac{r_{r}^{\prime}}{s a}\right)^{2}+X_{i^{2}}^{r^{2}}}}
$$

The electromagnetic torque is given by

$$
T_{e}=\frac{\left(\frac{r_{r}^{\prime}}{s a}\right)}{\left(\frac{r_{r}^{\prime}}{s a}\right)^{2}+X_{r_{r}^{2}}^{2}} \phi_{m}^{2}
$$

The stator current is related to the air gap flux and the electromagnetic torque as:

$$
I_{s}=\sqrt{\left(s_{1} \phi_{m}+s_{2} \phi_{m}^{3}+s_{3} \phi_{m}^{5}\right)^{2}+C_{L} \frac{T_{e}^{2}}{\phi_{m}^{2}}}
$$

Where

$$
C_{L}=1+2 \times \frac{x_{i r}^{\prime}}{x_{m}}
$$

The air gap flux is related to the electromagnetic torque as:

$$
\phi_{m}=\sqrt{\frac{s a}{r_{r}^{\prime}}} \sqrt{\left(\frac{r_{r}^{\prime}}{s a}\right)^{2}+x_{i r}^{\prime 2}} \sqrt{T_{e}}
$$


The efficiency is defined as the output power divided by the electric power supplied to the stator (inverter losses are included):

$$
\eta=\frac{P_{\text {out }}}{P_{\text {in }}}
$$

\subsubsection{Maximum Efficiency Strategy}

In MES (Maximum Efficiency Strategy), the slip frequency is adjusted so that the efficiency of the induction motor drive system is maximized.

The induction motor losses are the following:

1. Copper losses: these are due to flow of the electric current through the stator and rotor windings and are given by:

$$
P_{c u}=r_{s} I_{s}^{2}+r_{r}^{\prime} I_{r}^{\prime 2}
$$

2. Iron losses: these are the losses due to eddy current and hysteresis, given by

$$
\dot{P}_{\text {core }}=k_{e}\left(1+s^{2}\right) a^{2} \phi_{m}^{2}+k_{h}(1+s) a \phi_{m}^{2}
$$

3. Stray losses: these arise on the copper and iron of the motor and are given by:

$$
P_{s}=C_{s t r} \omega_{r}^{2} I_{r}^{\prime 2}
$$

4. Mechanical losses: these are due to the friction of the machine rotor with the bearings and are given by

$$
P_{f \omega}=C_{f \omega} \omega_{r}^{2}
$$

5. Inverter losses : The approximate inverter loss as a function of stator current is given by:

$$
P_{i n v}=K_{1 \text { inv }} i_{s}^{2}+K_{2 i n v} i_{s}
$$

Where: $\mathrm{K}_{1 \mathrm{inv}}, \mathrm{K}_{2 \text { inv }}$ are coefficients determined by the electrical characteristics of a switching element where: $\mathrm{K}_{1 \mathrm{inv}}=3.1307 \mathrm{e}-005, \mathrm{~K}_{2 \mathrm{inv}}=0.0250$.

The total power losses are expressed as:

$$
\begin{aligned}
& P_{\text {losses }}=P_{c u}{ }^{\prime}+P_{\text {core }}+P_{s}+P_{f w}+\dot{P}_{\text {iw }}=\left[r_{s}^{*} I_{s}^{2}+r_{r}^{\prime} I_{r}^{\prime 2}\right]+ \\
& +\left[k_{e}\left(1+s^{2}\right) a^{2} \phi_{m}^{2}\right]+\left[k_{h}(1+s) a \phi_{m}^{2}\right]+\left[\begin{array}{lll}
C_{s t r} & \omega_{r}{ }^{2} & I_{r}^{\prime 2}
\end{array}\right]+
\end{aligned}
$$

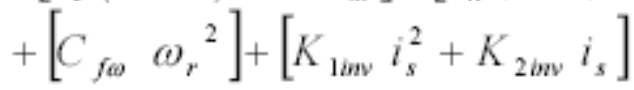


The output power is given by:

$$
P_{\text {out }}=T_{l} \times \omega_{r}
$$

The input power is given by:

$$
\begin{aligned}
P_{\text {in }}= & P_{\text {out }}+P_{\text {losses }}=\left[\begin{array}{ll}
r_{s} I_{s}^{2}+r_{r}^{\prime} I_{r}^{\prime 2}
\end{array}\right]+\left[k_{e}\left(1+s^{2}\right) a^{2} \phi_{m}^{2}\right]+ \\
& +\left[k_{h}(1+s) a \phi_{m}^{2}\right]+\left[\begin{array}{lll}
C_{s t r} & \omega_{r}^{2} & I_{r}^{\prime 2}
\end{array}\right]+\left[\begin{array}{ll}
C_{f \omega} & \omega_{r}^{2}
\end{array}\right]+ \\
& +\left[K_{1 i w v} i_{s}^{2}+K_{2 i n v} i_{s}\right]+T_{l} \times \omega_{r}
\end{aligned}
$$

The efficiency is expressed as:

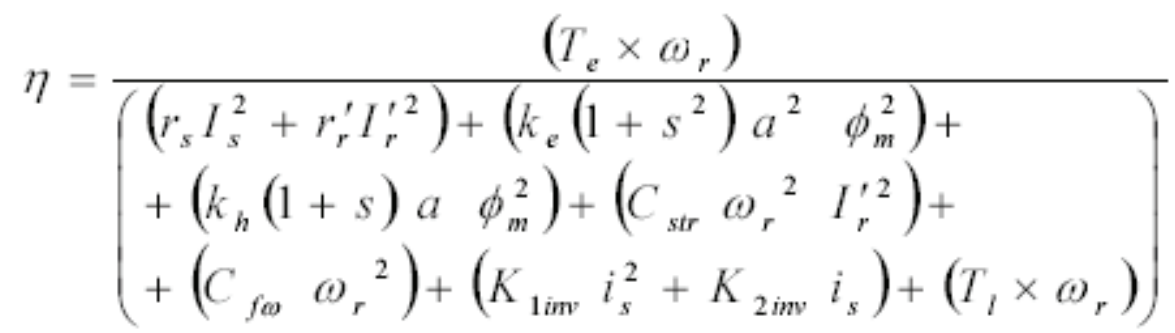

The efficiency maximization of the induction motor problem can be formulated as follows:

$$
\text { Maximize } \eta\left(T_{e}, \omega_{s}, \omega_{r}\right)
$$

The maximization should observe the fact that the amplitude of the stator current and flux cannot exceed their specified maximum point.

\subsubsection{Minimum Operating Cost Strategy}

In Minimum Operating cost Strategy (MOCS), the slip frequency is adjusted so that the operating cost of the induction motor is minimized. The operating cost of the induction machine should be calculated over the whole life cycle of the machine. That calculation can be made to evaluate the cost of the consumed electrical energy. The value of average energy cost considering the power factor penalties can be determined by the following stages:

1. If $0 \leq \mathrm{PF}<0.7$

$$
C=C_{0}\left[1+\left(\frac{0.9-P F}{0.01}\right) \times \frac{1}{100}\right]
$$


2. If $0.7 \leq \mathrm{PF} \leq 0.92$, If $\mathrm{PF} \geq 0.9, \mathrm{PF}=0.9$

$$
C=C_{0}\left[1+\left(\frac{0.9-P F}{0.01}\right) \times \frac{0.5}{100}\right]
$$

3. If $0.9 \leq \mathrm{PF} \leq 1$, If $0.95 \leq \mathrm{PF} \leq 1, \mathrm{PF}=0.95$

$$
C=C_{0}\left[1+\left(\frac{0.9-P F}{0.01}\right) \times \frac{0.5}{100}\right]
$$

If the average energy cost $C$ is calculated, it can be used to establish the present value of losses. The total cost of the machine is the sum of its initial cost plus the present worth value of losses and maintenance costs.

$$
P W_{L}=C \times T \times N \times P_{\text {out }} \times\left[\frac{1}{\eta}-1\right]
$$

Where:

$\mathrm{PW}_{\mathrm{L}}=$ present worth value of losses

$\mathrm{C}_{0}=$ energy cost $(\mathrm{L} . \mathrm{E} / \mathrm{KwH}), \mathrm{L} . \mathrm{E}$ is the Egyptian Pound

$\mathrm{C}=$ modified energy cost $(\mathrm{L} . \mathrm{E} / \mathrm{KwH})$

$\mathrm{T}$ = running time per year (Hrs / year)

$\mathrm{N}=$ evaluation life (years)

$\mathrm{P}_{\text {out }}=$ the output power (Kwatt)

$\eta \quad=$ the efficiency

The operating cost minimization of the induction motor problem can be formulated as follows:

$$
\text { Minimize } P W_{L}\left(T_{e}, \omega_{s}, \omega_{r}\right)
$$

The optimization in each case should observe the fact that the amplitude of the stator current and flux cannot exceed their specified maximum.

\subsection{Simulation Results}

The simulation is carried out on a three-phase, $380 \mathrm{~V}, 1-\mathrm{HP}, 50 \mathrm{~Hz}$, and 4-pole, squirrel cage induction motor. The motor parameters are $\mathrm{R}_{\mathrm{s}}=0.0598, \mathrm{X}_{\mathrm{ls}}=0.0364, \mathrm{X}_{\mathrm{m}}=0.8564, \mathrm{X}_{\mathrm{lr}}=0.0546$, $\mathrm{R}_{\mathrm{r}}=0.0403, \mathrm{~K}_{\mathrm{e}}=0.0380, \mathrm{~K}_{\mathrm{h}}=0.0380, \mathrm{C}_{\mathrm{str}}=0.0150, \mathrm{Cfw}=0.0093, \mathrm{~S} 1=1.07, \mathrm{~S}_{2}=-0.69, \mathrm{~S}_{3}=0.77$. For cost analysis, the following values were assumed: $\mathrm{C}_{0}=0.05, \mathrm{~N}=15, \mathrm{~T}=8000$. Figure 12 shows the efficiency variation with respect to the rotor and slip speed at various levels of load torque. At certain load torque and rotor speed, a certain value of slip frequency at which the maximum efficiency occurs is optimal. The task of PSO controller is to find that value of slip at which the maximum efficiency occurs. At certain load torque and rotor speed, the PSO controller determines the slip frequency $\omega_{\mathrm{s}}$ at which the maximum efficiency and minimum operating cost occur. The block diagram of the optimization process based on 
PSO is shown in fig.13. In the proposed controller, the PSO algorithm receives the rotor speed, load torque, and the fitness function (efficiency equation).

The PSO determines the slip frequency at which the maximum efficiency or minimum operating cost occurs at that rotor speed and load torque. Figures (14) and (15) show the efficiency of the machine as a function of the load torque and rotor speed under constant voltage to frequency ratio strategy and field oriented control strategy. From these figures it is obvious that, the efficiency decreases substantially when either the torque or rotor speed is small. On the other hand, fig. 16 shows the efficiency versus the load torque and rotor speed using the proposed technique (MES). This figure shows a great improving in efficiency especially at light loads and small rotor speed. To observe the improvements in efficiency using the suggested PSO controller, fig. 17 shows the efficiency of the selected machine for all operating conditions using conventional methods (constant voltage to frequency ratio, field oriented control strategy) and using the proposed PSO controller at different rotor speed levels, $\mathrm{W}_{\mathrm{r}}=0.2 \mathrm{PU}$, and $\mathrm{W}_{\mathrm{r}}=1 \mathrm{PU}$ respectively. This figure shows that a considerable energy saving is achieved in comparison with the conventional method (field oriented control strategy and constant voltage to frequency ratio). Table (1) shows the efficiency comparison using few examples of operating points.

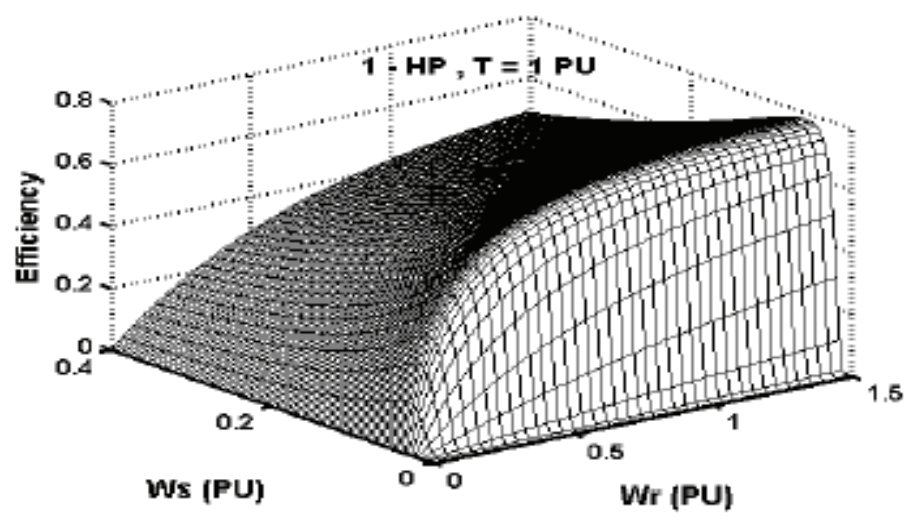

Figure 12. Efficiency versus rotor speed and slip speed at load torque $\mathrm{T}_{\mathrm{L}}=1 \mathrm{PU}$

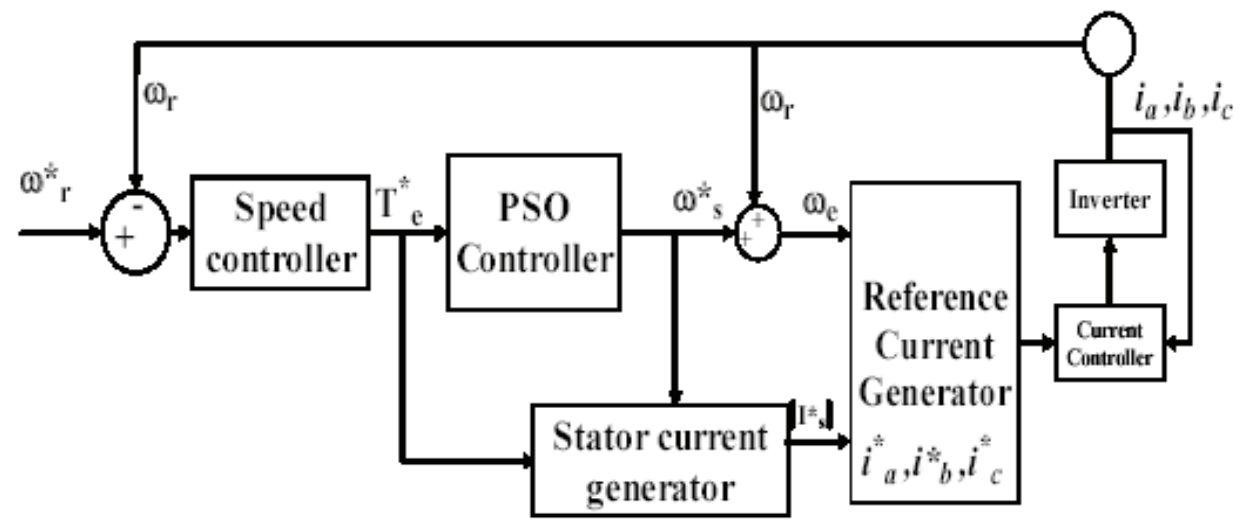

Figure 13. The proposed drive system based on PSO 


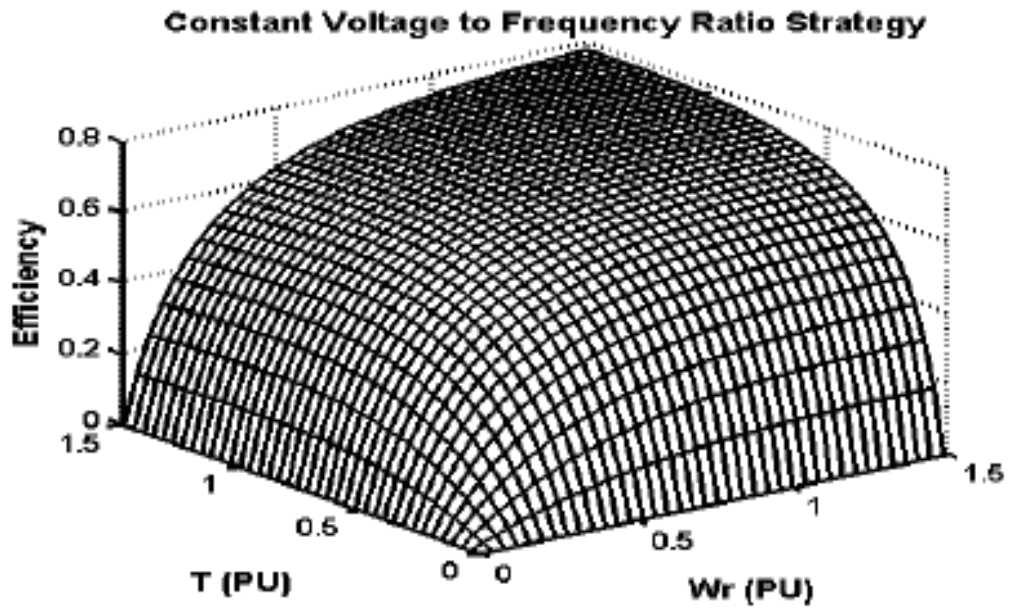

Figure 14. Efficiency versus rotor speed and load torque under constant voltage to frequency ratio strategy

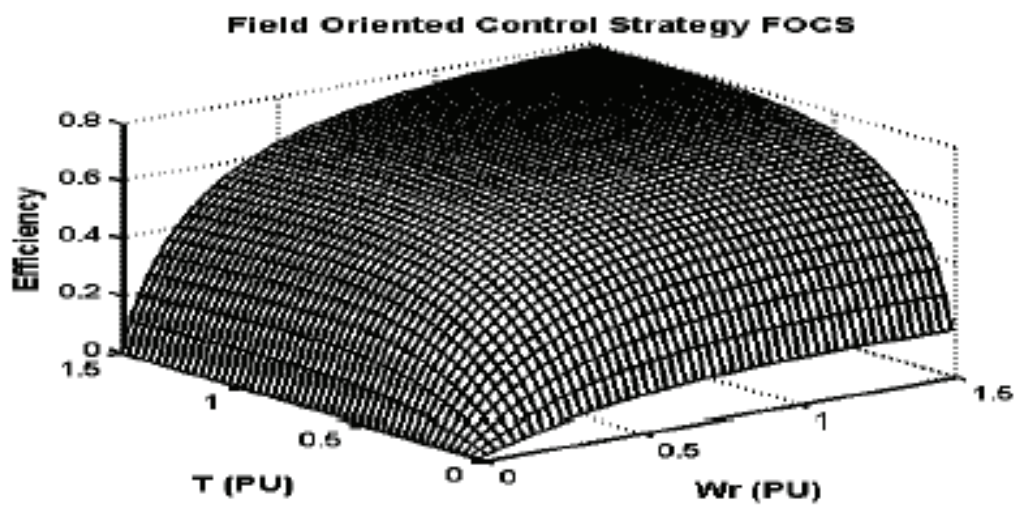

Figure 15. Efficiency versus rotor speed and load torque under field Oriented control strategy

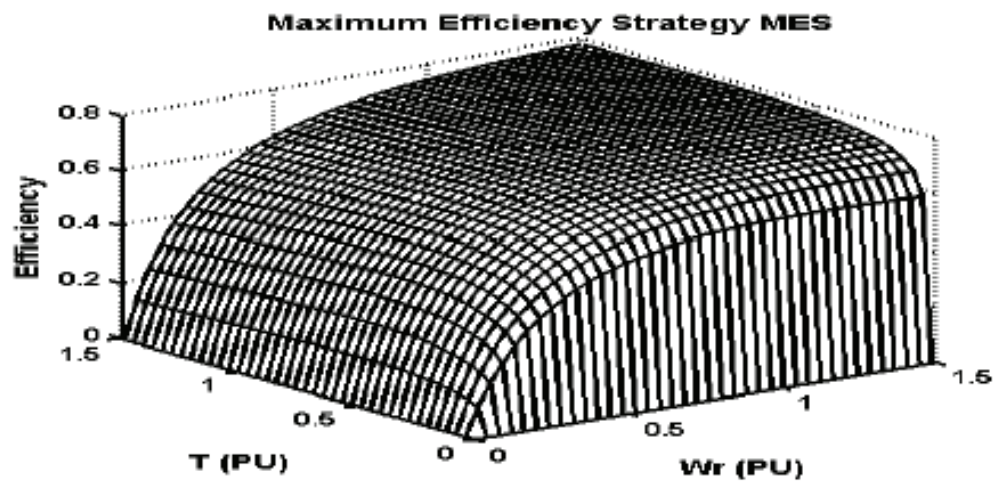

Figure 8. Efficiency versus rotor speed and load torque using the Proposed PSO controller (MES) 


\begin{tabular}{|c|c|c|c|c|}
\hline \multicolumn{5}{|c|}{ Efficiency comparison for $\omega_{\mathrm{r}}=1 \quad \mathrm{PU}$} \\
\hline $\mathrm{T}(\mathrm{PU})$ & $\begin{array}{c}\text { Constant } \\
\text { voltage to } \\
\text { frequency } \\
\text { ratio }\end{array}$ & $\begin{array}{c}\text { Field } \\
\text { oriented } \\
\text { control }\end{array}$ & $\begin{array}{c}\text { Maximum } \\
\text { efficiency } \\
\text { strategy }\end{array}$ & $\begin{array}{c}\text { Minimum } \\
\text { Operating } \\
\text { Cost } \\
\text { Strategy }\end{array}$ \\
\hline 0.2 & 0.5003 & 0.5330 & 0.7217 & 0.7193 \\
\hline 0.4 & 0.6482 & 0.6730 & 0.7506 & 0.7485 \\
\hline 0.6 & 0.7100 & 0.7271 & 0.7598 & 0.7584 \\
\hline 0.8 & 0.7384 & 0.7494 & 0.7618 & 0.7608 \\
\hline 1 & 0.7508 & 0.7569 & 0.7603 & 0.7595 \\
\hline 1.2 & 0.7544 & 0.7566 & 0.7568 & 0.7562 \\
\hline
\end{tabular}

Table 1. Some examples of efficiency comparison under different Load torque levels and $\mathrm{W}_{\mathrm{r}}=1 \mathrm{PU}$

Figure (10) compares the efficiency of the induction motor drive system under the maximum efficiency strategy with the minimum operating cost strategy at $W_{r}=0.2 \mathrm{PU}$ and $\mathrm{W}_{\mathrm{r}}=1 \mathrm{PU}$, respectively. It is obvious from the figure that the efficiency is almost the same for both strategies for all operating points. On the other hand, fig. 11 shows the percentage of the operating cost saving for the two strategies for $\mathrm{W}_{\mathrm{r}}=0.2$ and $\mathrm{W}_{\mathrm{r}}=1 \mathrm{PU}$ respectively. The percentage of the operating cost saving is calculated according to the following equation:

$$
\text { Saving }=\frac{P W_{\text {IMOCS }}-P W_{\text {IMES }}}{P W_{\text {IMES }}} \times 100 \%
$$

Where: $\mathrm{PW}_{\mathrm{IMES}}$ is the present worth value of losses under MES, and PW $\mathrm{WMOCS}_{\mathrm{IS}}$ is the present worth value of losses under MOCS. It is obvious from fig (11) that the saving has a noticeable value especially at light loads and rated speed that can as high as $11.2 \%$. It is clear that the PWL using the minimum operating cost strategy is less than the PWL using the maximum efficiency strategy. This difference in operating cost is shown in table (2). The reason for that difference is due to the difference in their power factor values. The difference in power factor values is shown in fig. 12 . 


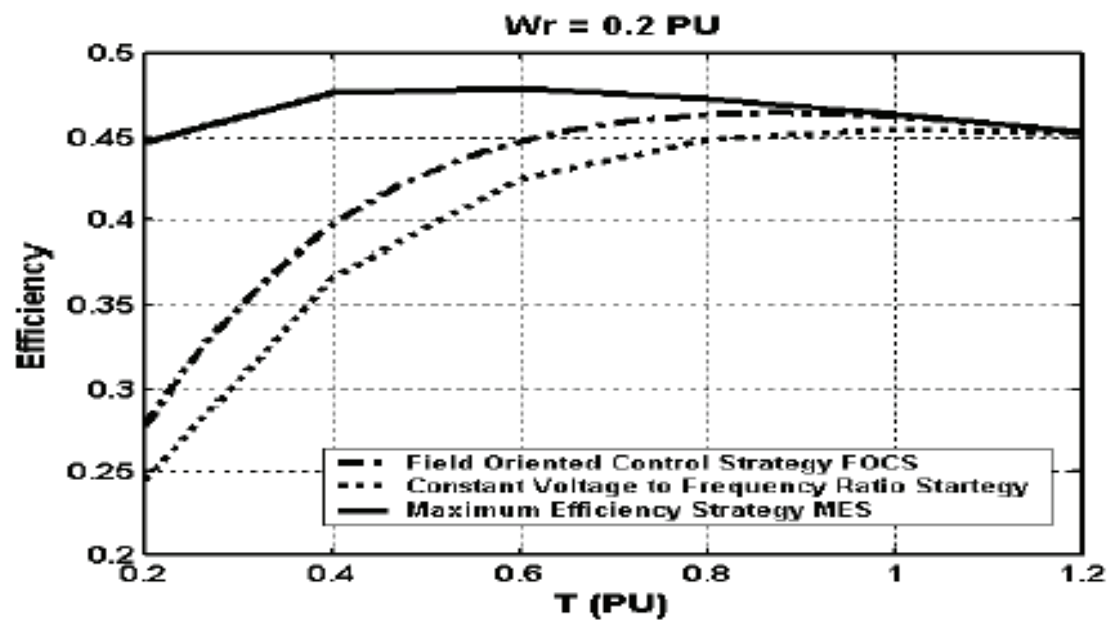

(a)

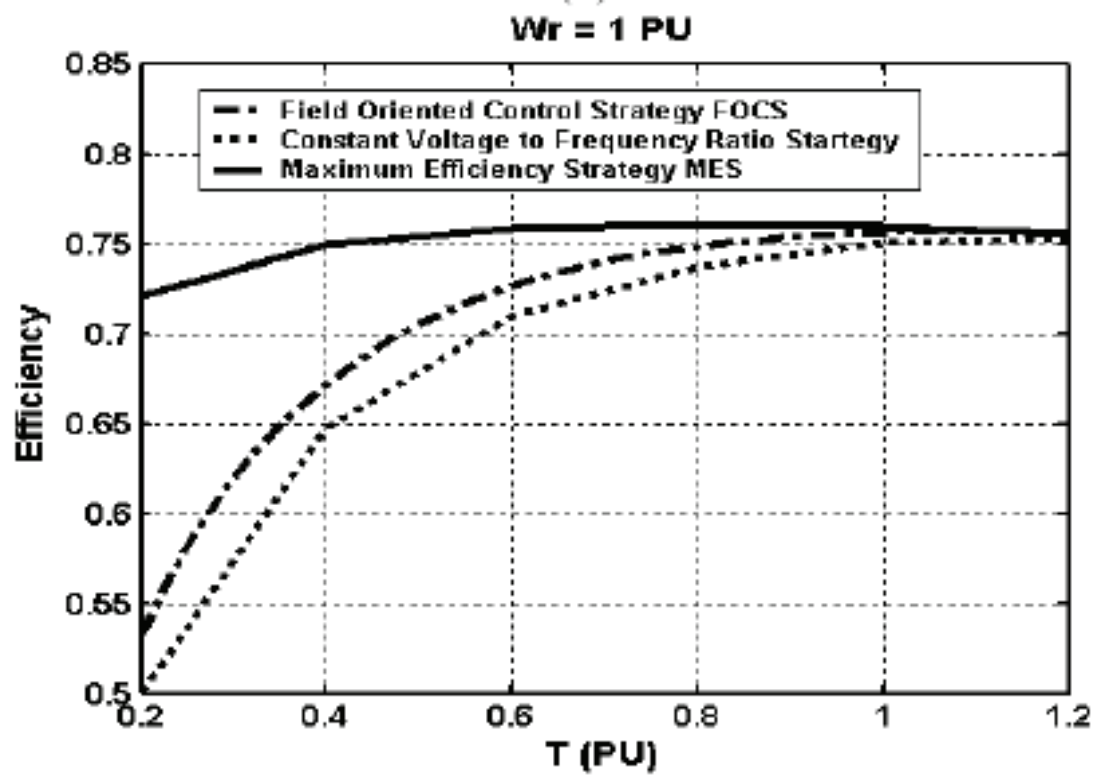

(b)

Figure 9. The efficiency of the induction motor using the maximum efficiency strategy compared with the efficiency using the conventional methods (field oriented control strategy and constant voltage to frequency ratio) for different rotor speed levels.

(a) $\mathrm{W}_{\mathrm{r}}=0.2 \mathrm{PU}, \quad$ (b) $\mathrm{W}_{\mathrm{r}}=1 \mathrm{PU}$ 


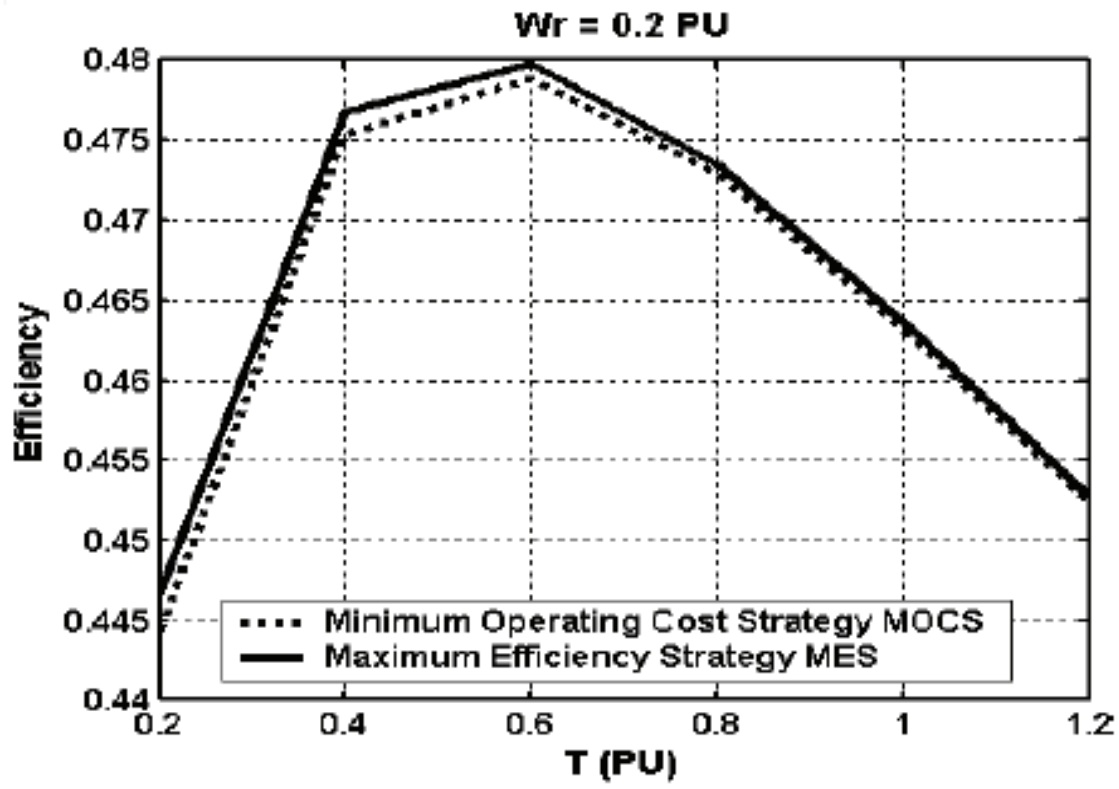

(a)

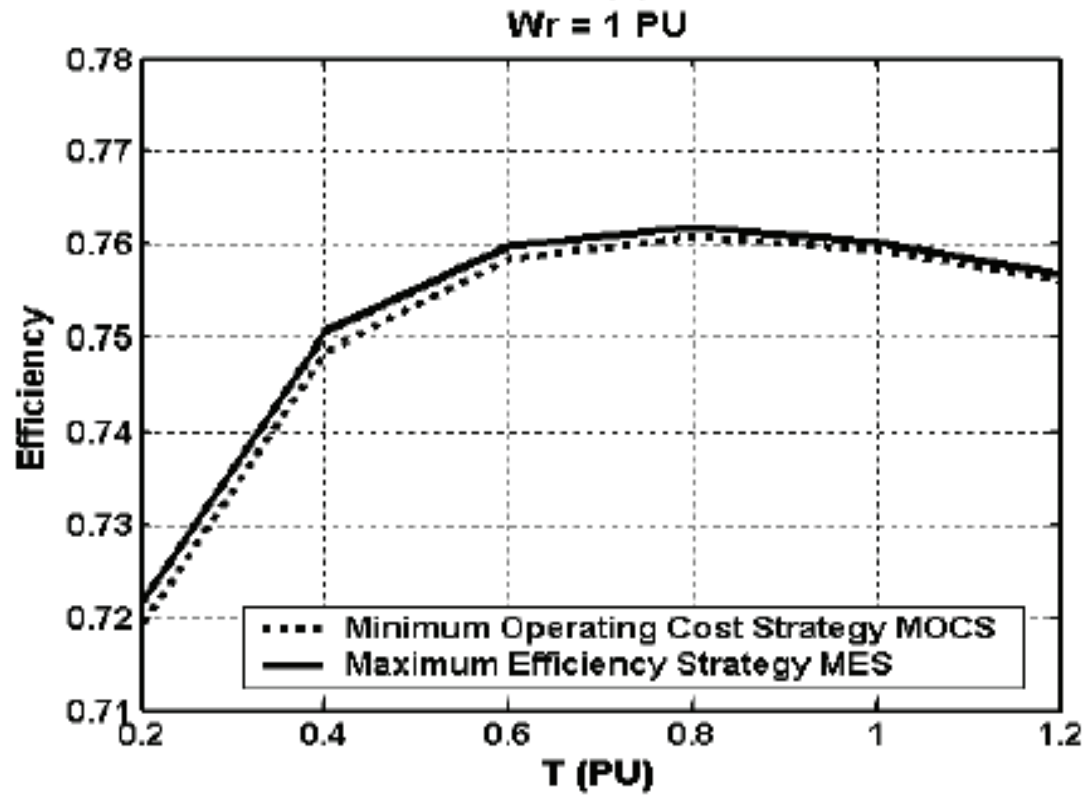

Figure 10. the efficiency of the induction motor using the maximum efficiency strategy compared with the efficiency using minimum operating cost strategy for different rotor speed levels. (a) $\mathrm{Wr}=0.2 \mathrm{PU}, \quad$ (b) $\mathrm{Wr}=1 \mathrm{PU}$ 


\begin{tabular}{|c|c|c|c|c|}
\hline \multicolumn{5}{|c|}{ Operating cost comparison (L.E) for $\omega_{\mathrm{r}}=1$ PU } \\
\hline $\mathrm{T}(\mathrm{PU})$ & $\begin{array}{c}\text { Constant } \\
\text { voltage to } \\
\text { frequency } \\
\text { ratio }\end{array}$ & $\begin{array}{c}\text { Field } \\
\text { oriented } \\
\text { control }\end{array}$ & $\begin{array}{c}\text { Maximum } \\
\text { efficiency } \\
\text { strategy }\end{array}$ & $\begin{array}{c}\text { Minimum } \\
\text { Operating } \\
\text { Cost } \\
\text { Strategy }\end{array}$ \\
\hline 0.2 & 1496494 & 1300954 & 432108 & 383515 \\
\hline 0.4 & 1486907 & 1308896 & 742514 & 661747 \\
\hline 0.6 & 1547089 & 1391272 & 1040340 & 937485 \\
\hline 0.8 & 1669655 & 1539698 & 1343879 & 1224637 \\
\hline 1 & 1848908 & 1748378 & 1535790 & 1529263 \\
\hline 1.2 & 1914440 & 1870885 & 1860518 & 1854120 \\
\hline
\end{tabular}

Table 2. Some examples of operating cost comparison under different load torque levels and $\mathrm{Wr}=1 \mathrm{PU}$

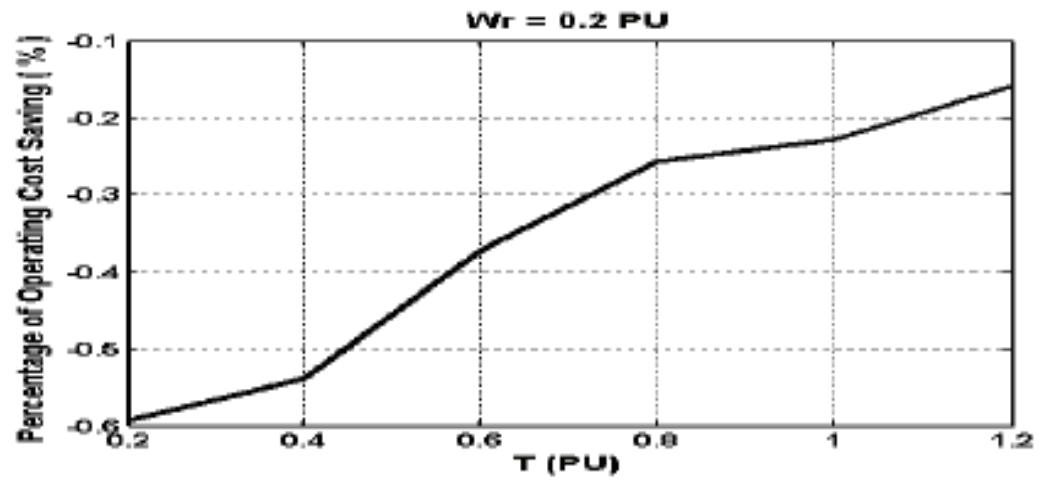

(a)

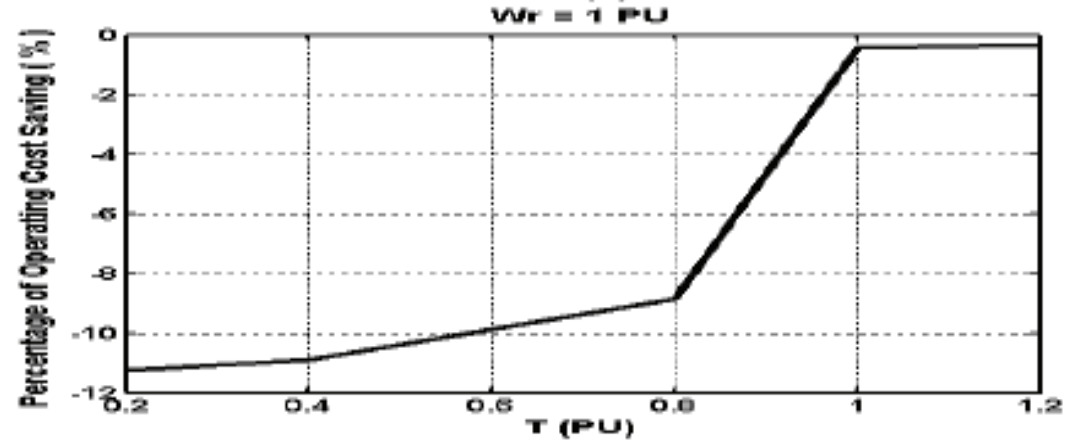

(b)

Figure 11. the $\mathrm{PW}_{\mathrm{L}}$ using maximum efficiency strategy compared with the PWL using the minimum operating cost strategy for different rotor speed levels.

(a) $\mathrm{Wr}=0.2 \mathrm{PU},(\mathrm{b}) \mathrm{Wr}=1 \mathrm{PU}$ 


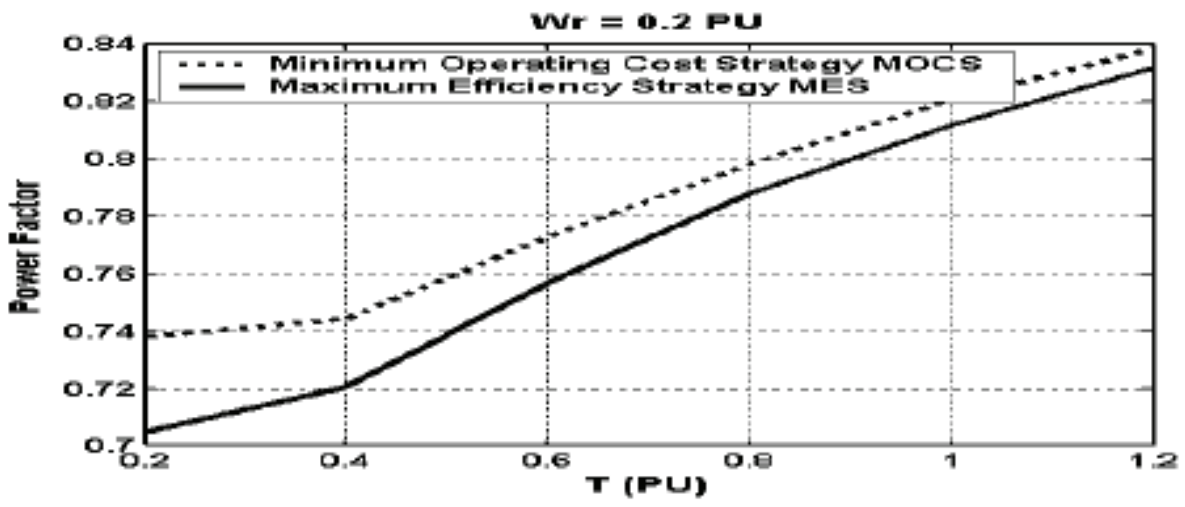

(a)

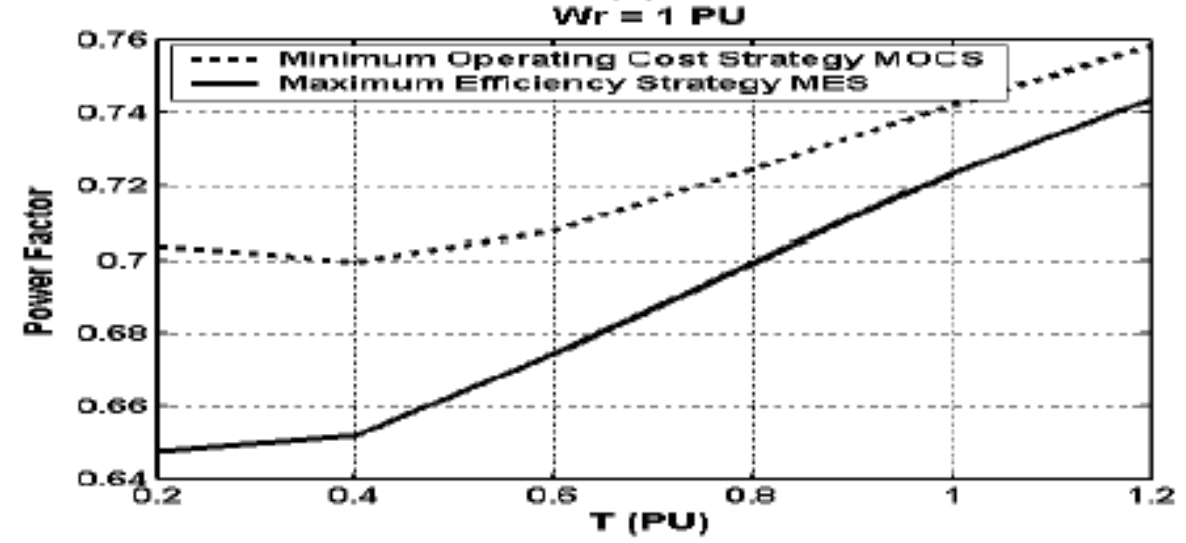

(b)

Figure 12. The Power factor of the induction motor using the maximum efficiency strategy compared with the Power factor using minimum operating cost strategy for different rotor speed levels, (a) $\mathrm{Wr}=0.2 \mathrm{PU}, \quad$ (b) $\mathrm{Wr}=1 \mathrm{PU}$

Finally, this section presents the application of PSO for losses and operating cost minimization control in the induction motor drives. Two strategies for induction motor speed control are proposed. Those two strategies are based on PSO and called Maximum Efficiency Strategy and Minimum Operating Cost Strategy. The proposed PSO-controller adaptively adjusts the slip frequency such that the drive system is operated at the minimum loss and minimum operating cost. It was found that the optimal system slip changes with variations in speed and load torque. When comparing the proposed strategy with the conventional methods field oriented control strategy and constant voltage to frequency ratio), It was found that a significant efficiency improvement It was found that a significant efficiency improvement is found at light loads for all speeds. On the other hand, small efficiency improvement is achieved at near rated loads. Finally, when comparing the MOCS with MES, it was found that, the saving in $\mathrm{PW}_{\mathrm{L}}$ using the MOCS is greater than that of the MES, especially at light loads and rated speed. 


\section{Particle Swarm Optimized Direct Torque Control of Induction Motors}

The flux and torque hysteresis bands are the only adjustable parameters in direct torque control (DTC) of induction motors. Their selection greatly influences the inverter switching loss, motor harmonic loss and motor torque ripples, which are major performance criteria. In this section, the effects of flux and torque hysteresis bands on these criteria are investigated and optimized via the minimization, by the particle swarm optimization (PSO) technique, of a suitably selected cost function. A DTC control strategy with variable hysteresis bands, which improves the drive performance compared to the classical DTC, is proposed. Online operating Artificial Neural Networks (ANNs) use the offline optimum values obtained by PSO, to modify the hysteresis bands in order to improve the performance. The implementation of the proposed scheme is illustrated by simulation results [9].

In this section, the effects of flux and torque hysteresis bands on inverter switching loss, motor harmonic loss and motor torque ripple of induction motor are investigated. To reduce speed and torque ripples it is desirable to make the hysteresis band as small as possible, thus increasing the switching frequency, which results in reduced efficiency of the drive by enlarging the inverter switching and motor harmonic losses. Hence, these hysteresis bands should be optimized in order to achieve a suitable compromise between efficiency and dynamic performance. In order to find their optimum values at each operating condition, a cost function combining losses and torque ripples is defined and optimized. A DTC control strategy with variable hysteresis bands is proposed, such that the optimum hysteresis band values are used at each operating condition. The proposed method combines the emerging Particle Swarm Optimization (PSO) for offline optimization of the cost function and the ANN technique for online determination of the suitable hysteresis band values at the operating point.

\subsection{DTC Performance Cost Function Optimization}

The design of the DTC involves the selection of suitable hysteresis band. In this section, the hysteresis band is selected so that it results in an optimal performance cost function. Since the optimal hysteresis bands depend on the operating conditions, the optimization procedure is implemented via PSO at several operating conditions that covers the possible working conditions of the drive system [9, 10, 11]. Fig. 13 shows the flow chart of the optimization method. A computer model of the overall drive system has been developed using MATLAB/SIMULINK software. The simulations have been performed for a $10 \mathrm{Hp}$ induction motor (the motor parameters are given in the appendix). The cost function is expressed as follows:

$$
C(\Delta T e, \Delta \lambda s)=W_{I} P_{L L}+W_{2} P_{c}+W_{3} \Delta T
$$

Where:

$\Delta$ Te: is the torque hysteresis band,

$\Delta \lambda \mathrm{s}$ : is the flux hysteresis band,

$\mathrm{P}_{\mathrm{IL}}$ : is inverter switching loss,

$\mathrm{P}_{\mathrm{C}}$ is core loss, and

$\mathrm{W}_{\mathrm{i}}$ : is a designer specified weighting factor. 
The weighting terms are selected to be $\mathrm{W}_{1}=0.2, \mathrm{~W}_{2}=0.2$ and $\mathrm{W}_{3}=0.6$. The reduction of torque ripples is the most important objective of the optimization. In the thirty-six different operating conditions, corresponding to the combination of six different speed and six different load torque values, are considered. The harmonic spectrum of the motor stator flux is calculated up to $30^{\text {th }}$ harmonic and the Simulink model is run for 2.5 seconds. For PSO, the following parameters are used: Size of the swarm $=10$, maximum number of iterations $=100$, maximum inertia weight's value $=1.2$, minimum inertia weight's value $=$ $0.1, C_{1}=C_{2}=0.5$,lower and upper bound for initial position of the swarm are 0 and 20 respectively maximum initial velocities value $=2$ and the weight vary linearly from 1.2 to 0.1. Table 1 presents the optimum torque and flux hysteresis bands (TB, and FB respectively) obtained by PSO.

\begin{tabular}{|c|c|c|c|c|c|c|c|c|c|c|c|}
\hline \multirow{2}{*}{$\omega_{\mathrm{r}}$} & \multicolumn{2}{|r|}{0} & \multirow{2}{*}{$\frac{1 / 5}{2}$} & \multicolumn{2}{|c|}{$2 / 5$} & \multicolumn{2}{|c|}{$3 / 5$} & \multicolumn{2}{|c|}{$4 / 5$} & \multicolumn{2}{|c|}{$5 / 5$} \\
\hline & B & F.B & & T.B & F.B & T.B & F.B & T.B & F.B & T.B & F.B \\
\hline & 17.9 & 4.99 & 15.61 .35 & 16.0 & 4.44 & 14.0 & 5.73 & 9.40 & 6.76 & 19.3 & 5.14 \\
\hline 86 & 12.4 & 1.45 & 13.20 .70 & 4.64 & 0.31 & 3.32 & 0.48 & 10.6 & 0.80 & 15.1 & 3.21 \\
\hline$/ / 6$ & 4.48 & 4.78 & 14.65 .61 & 13.2 & 13.3 & 15.9 & 12.7 & 15.0 & 12.3 & 4.01 & 1.04 \\
\hline$/ 6$ & 8.04 & 6.28 & \begin{tabular}{|l|l|}
14.48 .31 \\
\end{tabular} & 9.29 & 15.5 & 18.0 & 16.4 & 0.949 & 917.9 & 7.80 & 8.44 \\
\hline & 15.1 & 11.1 & \begin{tabular}{|l|l|}
7.72 & 15.3 \\
\end{tabular} & 16.2 & 8.79 & 6.04 & 6.19 & 14.4 & 3.97 & 14.4 & 3.57 \\
\hline & 2.75 & 6.61 & \begin{tabular}{|l|l|}
18.5 & 19.0 \\
\end{tabular} & 16.2 & 5.23 & 14.0 & 5.32 & 9.63 & 4.23 & 12.7 & 1.36 \\
\hline
\end{tabular}

Table 3. The optimum hysteresis bands obtained by PSO optimization process

\subsection{Neural Network Controller For DTC}

In the previous section, PSO is used as an offline optimization technique that determines the optimal values of the hysteresis bands. These bands depend on loading conditions. To ensure keeping the drive system running at the optimal performance cost function, the hysteresis band must be changed online depending on the current operating conditions. Neural networks (NNs) have good approximation ability and can interpolate and extrapolate its training data. Hence, to achieve the online selection of the hysteresis bands, two neural networks are trained by the offline optimum results obtained by PSO for flux and torque bands respectively. The inputs of these $\mathrm{NN}$ are the desired motor speed and the desired load torque.

The two considered NN's are Feed-forward type networks. Each NN has two inputs, one output, and two layers. The flux neural network has 8 neurons in the input layer and one neuron in the output layer. The torque neural network has 9 neurons in the input layer and one neuron in the output layer. The activation function of the hidden layer is log sigmoid while the output layer is linear. For both networks, the Neural Network Matlab Toolbox is used for the training. The training algorithm selected is Levenberg-Marquarbt back propagation, the adaptation learning function is "trains" sequential order incremental update, and the performance function is the sum-squared error. 


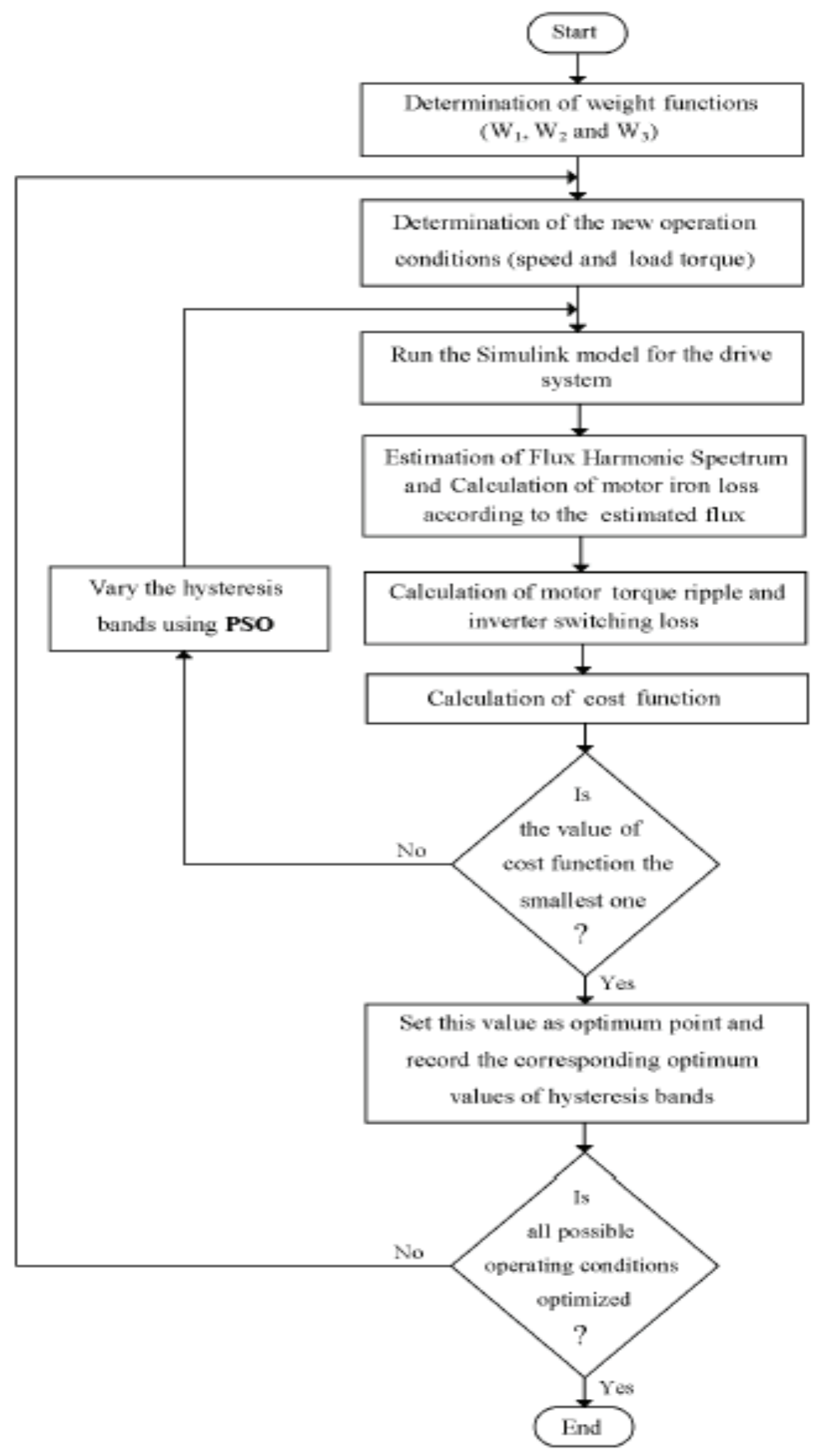

Figure 13. The flow chart of the optimization process 


\subsection{Comparison Between Classical and the Neural Network Controller for DTC}

Simulations have been performed for the above mentioned $10 \mathrm{Hp}$ induction motor to compare between the classical and the neural network controller for direct torque controlled IM. For classical DTC the results have been obtained for flux and torque hysteresis band amplitude equal to $2 \%$. In neural network Controller the above flux and torque neural networks are used to set the optimal hysteresis bands. Fig. 14 and Fig. 15 show the simulation results for the classical and the neural network controller respectively for a test run that covers wide operating range. It is clear that, the proposed scheme achieves a considerable reduction in inverter switching loss, motor harmonic loss, and motor torque ripple of the direct torque controlled induction motor drives compared to the Classical DTC. Table 4 shows the comparison between classical DTC and NN DTC

\begin{tabular}{|ccccc|}
\hline & Swt. Loss & Iron Loss & T. Ripples & Cost Fun. \\
Classical DTC & 0.4169 & 0.7606 & 0.9568 & 0.80958 \\
NN optimized DTC & 0.3545 & 0.6706 & 0.4522 & 0.47634 \\
\hline
\end{tabular}

Table 4. Comparison between classical and NN controller for DTC
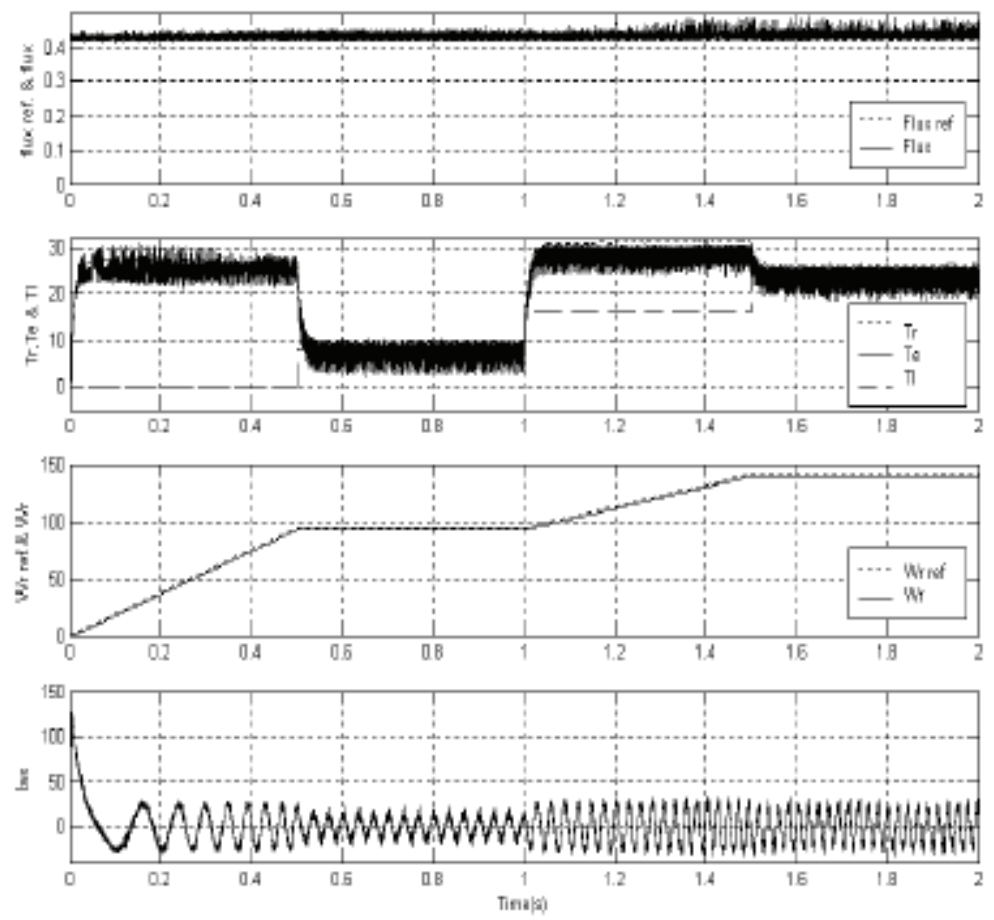

Figure 14. The classical direct torque controlled IM simulation results 

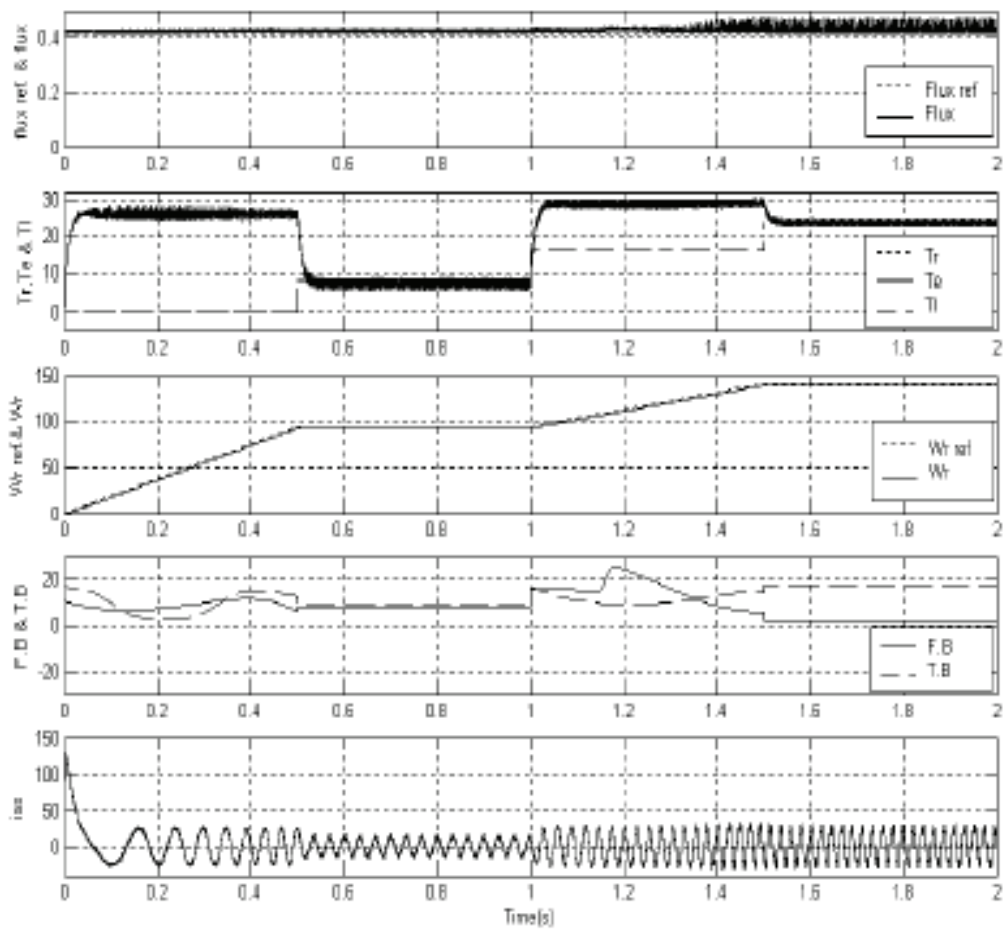

Figure 15. The neural network direct torque controlled IM simulation results

Finally, the DTC control strategy with variable hysteresis bands, which improves the drive performance compared to the classical DTC, is proposed. Particle swarm optimization is used offline to minimize a cost function that represents the effect of the hysteresis band on the inverter switching loss, motor harmonic loss and motor torque ripples at different operating conditions. Online operating ANNs use the offline optimum values obtained by PSO, to decide the suitable hysteresis bands based on the current operating condition. Simulation results indicate the validity of the proposed scheme in achieving better performance of the drive system in a wide operating range.

\section{Index I}

List of principal symbols

$\begin{array}{ll}\omega_{e} & : \text { synchronous speed } \\ \omega_{r} & : \text { rotor speed } \\ p & : \text { differential operator } \\ r_{m}, r_{a} & : \text { main, auxiliary stator windings resistance } \\ r_{r} & : \text { rotor winding resistance } \\ R_{f e q, d} & : \text { equivalent iron-loss resistance(d and q axis) } \\ L_{l m}, L_{l a} & : \text { main, auxiliary stator leakage inductance }\end{array}$




$\begin{array}{ll}L_{m d}, L_{m q} & : \text { magnetizing inductance (dE } q \text { axis) } \\ L_{l r} & : \text { rotor leakage inductance } \\ K & : \text { turns ratio auxiliary/main windings } \\ T_{e} & : \text { electromagnetic torque } \\ J & : \text { inertia of motor } \\ \lambda_{d s, q s} & : \text { stator flux (d and q axis) } \\ \lambda_{d r, q r} & : \text { rotor flux (d and q axis) } \\ V_{d s, q s} & : \text { stator voltage (d and q axis) } \\ i_{d s, q s} & : \text { stator current (d and q axis) } \\ M & : \text { mutual inductance }\end{array}$

\section{References}

A. M. A. Amin, M. I. Korfally, A. A. Sayed, and O.T. M.Hegazy, Losses Minimization of Two Asymmetrical Windings Induction Motor Based on Swarm Intelligence, Proceedings of IEEE-IECON 06 , pp 1150 - 1155, Paris , France , Nov. 2006 . [1]

A. M. A. Amin, M. I. Korfally, A. A. Sayed, and O.T. M.Hegazy, Swarm Intelligence-Based Controller of Two-Asymmetrical Windings Induction Motor, accepted for IEEE. EMDC07, pp 953 -958, Turkey, May 2007. [2]

M. Popescu, A. Arkkio, E. Demeter, D. Micu, V. Navrapescu. Development of an inverter fed two-phase variable speed induction motor drive, in Conference Records of PEMC'98, pp.4-132 - 4-136 Sept. 1998, Prague, Czech Republic ISBN-80-01-01832-6. [3]

Ahmed A. A. Esmin, Germano Lambert-Torres, and Antônio C. Zambroni de Souza, A Hybrid Particle Swarm Optimization Applied to Loss Power Minimization IEEE Transactions on Power Systems, Vol. 20, No. 2, May 2005. [4]

Radwan H. A. Hamid, Amr M. A. Amin, Refaat S. Ahmed, and Adel A. A. El-Gammal, New Technique For Maximum Efficiency And Minimum Operating Cost Of Induction Motors Based On Particle Swarm Optimization (PSO), Proceedings of IEEE-IECON 06 , pp 1029 - 1034, Paris , France , Nov. 2006. [5]

Zhao, B.; Guo, C.X.; Cao, Y.J.; A Multiagent-Based Particle Swarm Optimization Approach For Optimal Reactive Power Dispatch,Power Systems, IEEE Transactions on Volume 20, Issue 2, May 2005 Page(s):1070 - 1078. [6]

Cui Naxin; Zhang Chenghui; Zhao Min; Optimal Efficiency Control Of Field-Oriented Induction Motor Drive And Rotor Resistance Adaptive Identifying, Power Electronics and Motion Control Conference, 2004. IPEMC 2004. The 4th International Volume 1, 2004. [7]

Chakraborty, C.; Hori, Y.; Fast Efficiency Optimization Techniques for the Indirect VectorControlled Induction Motor Drives, Industry Applications, IEEE Transactions on, Volume: 39, Issue: 4, July-Aug. 2003 Pages: 1070 - [8]

O. S. El-Laban, H. A. Abdel Fattah, H. M. Emara, and A. F. Sakr, Particle Swarm Optimized Direct Torque Control of Induction Motors, Proceedings of IEEE- IECON 06 , pp 1586 - 1591, Paris , France , Nov. 2006 . [9] 
S. Kaboli, M.R. Zolghadri and A. Emadi, Hysteresis Band Determination of Direct Torque Controlled Induction Motor Drives with Torque Ripple and Motor-Inverter Loss Considerations. Proceeding of the 34th IEEE Power Electronics Specialists Conference, PESC03, June 2003, pp. 1107,1111. [10]

S. Kaboli, M.R. Zolghadri, S. Haghbin and A. Emadi, Torque Ripple Minimization in DTC of Induction Motor Based on Optimized Flux value Determination, Proceeding of 29th Conference of IEEE Industrial Electronics Society IECON03, pp.431-435. [11] 


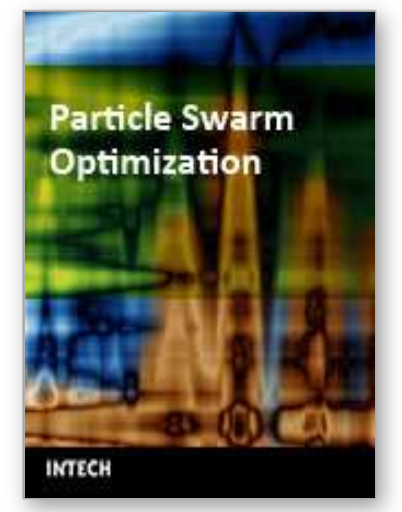

\author{
Particle Swarm Optimization \\ Edited by Aleksandar Lazinica
}

ISBN 978-953-7619-48-0

Hard cover, 476 pages

Publisher InTech

Published online 01, January, 2009

Published in print edition January, 2009

Particle swarm optimization (PSO) is a population based stochastic optimization technique influenced by the social behavior of bird flocking or fish schooling.PSO shares many similarities with evolutionary computation techniques such as Genetic Algorithms (GA). The system is initialized with a population of random solutions and searches for optima by updating generations. However, unlike GA, PSO has no evolution operators such as crossover and mutation. In PSO, the potential solutions, called particles, fly through the problem space by following the current optimum particles. This book represents the contributions of the top researchers in this field and will serve as a valuable tool for professionals in this interdisciplinary field.

\title{
How to reference
}

In order to correctly reference this scholarly work, feel free to copy and paste the following:

Amr M. Amin and Omar T. Hegazy (2009). Swarm Intelligence Applications in Electric Machines, Particle Swarm Optimization, Aleksandar Lazinica (Ed.), ISBN: 978-953-7619-48-0, InTech, Available from: http://www.intechopen.com/books/particle_swarm_optimization/swarm_intelligence_applications_in_electric_m achines

\section{INTECH}

open science | open minds

\section{InTech Europe}

University Campus STeP Ri

Slavka Krautzeka 83/A

51000 Rijeka, Croatia

Phone: +385 (51) 770447

Fax: +385 (51) 686166

www.intechopen.com

\section{InTech China}

Unit 405, Office Block, Hotel Equatorial Shanghai

No.65, Yan An Road (West), Shanghai, 200040, China

中国上海市延安西路65号上海国际贵都大饭店办公楼405单元

Phone: +86-21-62489820

Fax: +86-21-62489821 
(C) 2009 The Author(s). Licensee IntechOpen. This chapter is distributed under the terms of the Creative Commons Attribution-NonCommercialShareAlike-3.0 License, which permits use, distribution and reproduction for non-commercial purposes, provided the original is properly cited and derivative works building on this content are distributed under the same license. 